ÉGYPTE monde arabe

\section{Égypte/Monde arabe}

$7 \mid 1991$

Perceptions de la centralité de l'Égypte 1

\title{
Centralité de la musique égyptienne
}

\section{Philippe Vigreux}

\section{(2) OpenEdition}

\section{Journals}

Édition électronique

URL : https://journals.openedition.org/ema/1157

DOI : 10.4000/ema. 1157

ISSN : 2090-7273

\section{Éditeur}

CEDEJ - Centre d'études et de documentation économiques juridiques et sociales

\section{Édition imprimée}

Date de publication : 30 septembre 1991

Pagination : 55-101

ISSN : 1110-5097

\section{Référence électronique}

Philippe Vigreux, «Centralité de la musique égyptienne », Égypte/Monde arabe [En ligne], 7| 1991, mis en ligne le 08 juillet 2008, consulté le 07 juillet 2022. URL : http://journals.openedition.org/ema/1157 ; DOI : https://doi.org/10.4000/ema.1157

Ce document a été généré automatiquement le 7 juillet 2022.

Tous droits réservés 


\title{
Centralité de la musique égyptienne
}

\author{
Philippe Vigreux
}

1 Que dans les domaines de la musique et de la chanson, l'Égypte ait pendant trois quarts de siècle (1904-1975) véhiculé dans le reste du monde arabe un modèle culturel, voilà qui relève de l'évidence. S'il y a toujours quelque arbitraire, quelque inconséquence, à borner des phénomènes culturels complexes dans les limites de dates précises, expliquons-nous sur les nôtres. La première, concrètement, marque les débuts de l'industrie du disque en Égypte, la seconde, plus symbolique, l'extinction de la plus grande voix arabe de ce siècle.

2 Nombreux ont été les facteurs et les vecteurs de cette hégémonie :

1. Facteurs historiques, économiques, démographiques ;

2. Vecteurs médiatiques : disque, cinéma, radio ;

3. Vecteur politique.

Pendant la période considérée, des générations de poètes, de musiciens et de chanteurs ont façonné et transmis un idiome musical qui s'est imposé au reste du monde arabe et que l'on a souvent considéré, par l'allégeance portée à ses grandes voix, comme la seule manifestation de son unité.

4 Traiter de la centralité musicale de l'Égypte, c'est avant tout définir un langage musical et retracer l'histoire de son élaboration. C'est être frappé aussi par un caractère de massivité engendrant, dans le discours porté sur lui, une même globalité qui gomme les distinctions entre les genres (les intellectuels arabes ou européens parlent de « chanson sirupeuse égyptienne»), massivité liée à l'extraordinaire système de production artistique mis en place par l'Égypte dès les années 30 et, parallèlement, à l'inexistence d'un tel système dans d'autres pays arabes ${ }^{1}$. Or, même s'il s'impose dans l'aire considérée sur une période pouvant être estimée entre le tout début du siècle et le début des années 80 , ce langage est le fruit d'un accouchement troublé, fait de ruptures, d'arrêts brutaux de son histoire, de manipulations idéologiques. Vu de l'intérieur, ce solide rayonnement dévoile en son coeur bien des turbulences. Il ne saurait en être autrement dès lors que la période qui va de la renaissance musicale égyptienne (nahda) jusqu'à la période récente voit poindre sur cette terre d'Égypte le défi posé par là 
modernité. La musique n'a pas échappé à cette interpellation. Présence notable de la musique européenne dès l'époque de la nahda - la naissance d'une spécificité musicale égyptienne s'opère dans une ambiance de cosmopolitisme total et il est vrai que dès le départ elle s'insère (spatialement!) entre musique turque et musiques occidentales ${ }^{2}$-, arrivée brutale et massive des nouveaux media nés de la technique européenne, des formes d'expression artistique européennes (théâtre, opéra, café-concert), apport de la pensée occidentale moderne (rationalisme): l'éternel problème 'asâla-hadâtha (authenticité-modernité) se présente à tous les détours de l'analyse.

Nous nous proposons dans cet article d'examiner le rayonnement de la musique égyptienne dans le monde arabe, ses vecteurs. Or, il nous faut d'emblée relever un premier paradoxe : c'est à l'heure où celle-ci déborde le plus largement ses frontières, en d'autres termes acquiert cette durable position de centralité, qu'elle connaît sa phase de plus brûlant et de plus crucial questionnement. D'abord sur son système (Congrès de musique arabe de 1932), puis sur son essence même (débat idéologique qui perce au lendemain de la révolution de 1952).

6 Déjà, vers 1850, les liens et la communauté d'idées d'un 'Abduh al-Hamûlî, chef de l'école khédiviale (dénomination courante mais pouvant prêter à l'amalgame) avec le cheikh Muhammad 'Abduh placent l'expérience d'individualisation et d'élaboration d'une musique égyptienne au cœur de la problématique réformiste. Par là, considérant cette première période, puis les soubresauts ultérieurs, c'est plus d'un siècle de réforme qui s'ouvre à nous. Chose inattendue, une étude approfondie de l'émergence d'une centralité musicale de l'Égypte ne pourrait ignorer cette tendance et c'est une chronologie du réformisme musical en Égypte que nous voudrions esquisser ici, en attendant une étude plus spécifique.

7 Par ailleurs, second paradoxe, sans doute non isolé et circonscrit à l'Égypte mais revêtant ici un caractère aigu: ce sont les vecteurs mêmes de cette centralité qui bouleversent les structures de la musique et de la chanson. Fait remarquable, l'évolution des formes suit chronologiquement la domination successive de chacun de ces media, lequel impose définitivement ses critères et joue sur l'évolution des goûts :

1. Le disque qui, par les moyens techniques qu'il offre, contribue à la disparition des formes improvisatives.

2. Le théâtre ou l'exigence d'une nouvelle expressivité marquée par l'intégration du chant à un récit.

3. Le cinéma : intégration de la chanson dans le film et autonomie parallèle de la chanson comme produit indépendant.

8 Nous ne ferons qu'évoquer ici, pour la logique de l'exposé, ce second paradoxe, un certain nombre d'auteurs s'étant attachés dans des travaux de valeur à l'étude de l'influence des media considérés sur l'évolution du langage musical égyptien ${ }^{3}$.

\section{Premier jalon pour une chronologie de la réforme musicale en Égypte}

9 Évoquer la position centrale de l'Égypte dans le monde arabe pour ce qui concerne la chanson, dite «savante " ou de variété, le film musical, c'est, dans la conscience de tous, faire référence à une tranche historique relativement précise, celle qui va, grosso modo, de l'entre-deux-guerres jusqu'à nos jours. Cette période, en effet, correspond 
dans la musique et la chanson arabes à une redéfinition des formes, à l'élaboration d'un nouveau langage, aussi bien dans le domaine de la mélodie et des textes que dans la conception du rôle de l'orchestre. C'est la musique née de ce travail d'expérimentation (d'autres diront de sape en profondeur !) qui va inonder le monde arabe, portée par des moyens médiatiques nouveaux et d'une puissance sans précédent. Mais n'examiner que cette période, centrale pour notre sujet, serait faire injustice à un premier effort d'élaboration qui a marqué le tournant de notre siècle. Ce serait ignorer par quel processus la musique égyptienne a mérité son nom, s'individualisant par rapport à l'ottomane dont elle hérite cependant une partie de son système modal et rythmique. Cette période a renouvelé des formes anciennes qui ont vite formé le fonds d'une riche tradition. Ce sont ces formes (le dawr particulièrement) qui ont fondé les bases de la centralité dont nous parlons.

Jurjî Zaydân est l'un des rares auteurs à évoquer la nahda sans dissocier la littérature du fait musical. Il écrit ${ }^{4}$ : «Il s'est produit au sein de cette renaissance (i.e littéraire) un mouvement intellectuel et musical (haraka fikriyya mûsîiyya). La musique a été affectée d'un changement dicté par les conditions sociales. Un groupe de musiciens et de chanteurs s'est illustré, à la tête duquel 'Abduh al-Hamûlî, promoteur de la nouvelle manière de chanter en Égypte ». L'histoire retient qu'au XI ${ }^{\mathrm{e}}$ siècle de l'hégire, un Alépin nommé Châker Effendi s'était rendu en Égypte et y avait apporté les derniers vestiges du chant arabe de l'âge d'or hérités par les Alépins et composés de tawâchîh et de qudûd. C'est cet héritage, gardé intact au long des siècles suivants, que 'Abduh al-Hamûlî aurait recueilli pour y imprimer la marque de son interprétation. Sa renommée grandissant, al-Hamûlî est le premier chanteur arabe associé à la cour du khédive Isma'îl. C'est certainement là que commence pour la musique et le chant égyptiens une nouvelle histoire. Al-Hamûlî accompagne plusieurs fois le khédive à Istanbul et y écoute instrumentistes et chanteurs turcs. Il est indéniable que ce séjour à la cour khédiviale et ces voyages répétés dans la capitale de la Porte ont via al-Hamûlî et les autres grands chanteurs et musiciens du XIXe siècle, invités à se produire au palais Yildîz, tels Yûsuf al-Manyalâwî, Muhammad 'Uthmân, Muhammad Sâlim, al-Chantûrî, al-Baghdâdî, al-'Aqqâd et Ibrâhîm Sahlûn ${ }^{5}$ - doté la musique égyptienne d'apports décisifs et ceci dans trois domaines au moins :

1. Élargissement du répertoire maqâmien : certains modes jusqu'alors inconnus en Égypte sont adoptés, en particulier le nahawand (équivalent de notre mode mineur), le hijâz kâr, le rast et le 'ajam.

2. Art de moduler au cours d'un même chant, ce qui aura une importance décisive dans l'évolution du dawr.

3. Élargissement du répertoire rythmique (surtout au profit du muwachchah).

4. Se tournant ensuite vers les formes de chant locales, celles des munchidîn (ou hymnodes, connus alors sous le nom de 'awlâd al-layâlî) et des maddâhîn, louangeurs du Prophète (addâribîn bi-d-dufûf), il opère une synthèse qui fonde la musique égyptienne. Nous ne savons en fait que peu de choses sur la période qui précède la formation de ce " classicisme » égyptien. Il est probable qu'ici comme ailleurs, au Maghreb par exemple avec le malûf (répertoire classique arabo-andalou, Tunisie, Libye), les écoles de chant coranique et les confréries sont le lieu de conservation du répertoire et de transmission des règles du chant.

11 Il faut noter dès maintenant à ce propos le total décloisonnement qui existe pendant la nahda entre chant sacré et chant profane. Cette tradition classique voit se côtoyer cheikhs et effendis, ceux-ci ayant été formés à l'école de ceux-là. En retour, les cheikhs sont attirés par le chant profane des effendis. Ceci pose un problème d'ordre 
sociologique. Comment concevoir que des religieux franchissent si aisément la frontière, épaisse au plan de la loi, qui sépare le chant sacré du chant profane, ceci en vertu d'une fiction juridique savamment établie par les fuqahâ' (juristes) et tendant à faire admettre que le tajwîd ou le taghbîr (cantilation du Coran) diffèrent du ghinấ'. De plus, en choisissant un répertoire profane et en s'entourant d'instruments de musique, prohibés à des degrés divers par les écoles de droit canonique, on accède au statut de fannân (artiste). Or, ce statut, dans la société de l'époque, n'est guère enviable semble-til. Partant du principe que la nature d'un métier influe sur l'esprit de celui qui l'exerce (et le métier d'artiste est regardé comme frivole), le témoignage du fannân est reconnu comme nul par l'école hanéfite, jusqu'à ce qu'une loi votée dans les années quarante vienne abroger cette disposition. Il faudrait assurément ici mettre au point une question de vocabulaire et définir plus précisément ce que recouvre le titre de cheikh. Il y a cheikh et cheikh. Le grand cheikh est rattaché à al-Azhar par un titre officiel, sanctionnant de longues années d'études et d'approfondissement de la loi religieuse, "toutes choses à même de le tenir éloigné des pratiques illicites ", déclare selon une casuistique cynique un muftî d'al-Azhar consulté à ce propos. Parmi les machâyikh (cheikhs) qui, pendant la nahda, s'illustrent dans l'art du chant (Cheikh Yûsuf alManyalâwî, Cheikh Sayyid al-Saftî, Cheikh Ahmad Hasanayn, Cheikh 'Alî al-Hârith, Cheikh Muhammad Abû al-'Ilâ, Cheikh Salâma Higâzî, Cheikh Sayyid Darwîch, etc., presque aucun ne possède cette qualité. La plupart ont occupé quelque temps la fonction de muqri' («lecteur» de Coran) d'une mosquée de quartier. Ils sont de plus "hâfiz» (sachant le Coran par coeur), ce qui suffit à leur concéder le titre de cheikh. Pour eux, la transgression, c'est-à-dire le passage au chant profane ne représente pas, en terme de statut social, un sacrifice.

Existe-t-il dans le registre des textes un élément discriminatoire? Peut-on penser que ces machâyikh viennent au chant profane avec d'autant plus de facilité que la langue de ces chansons, classique ou dialectale, laisse assez d'ambiguïté entre amour humain et amour divin? Toute une tradition poétique soufie certes (ces cheikhs sont hymnodes de confrérie), exprime l'amour divin par des termes relevant d'une sensualité profane (Ibn al-Fârid). On retrouvera cette tradition conservée chez Umm Kulthûm (Rubâ'iyyât al-Khayyâm, Râmi/Sunbâti). Il faudrait ici introduire une discrimination qui est celle du genre. Une des conventions permettant cette perméabilité des deux registres est le strict emploi du masculin désignant l'être aimé. Masculin devant être considéré comme une métaphore du voile dans la qasida profane (voile grammatical) ou comme un neutre renvoyant à la figure insaisissable, inqualifiable, de l'Aimé6. La plupart du temps, l'ambiguïté du genre est contournée par la métaphorisation, la métonymisation. La source de l'amour ('asl al-gharâm), ce qui l'a provoqué, n'est pas le spectacle de l'aimé(e) mais d'une partie de sa personne (taille, joue, regard). Nombre de qasida-s miamoureuses mi-religieuses des débuts de Salâma'Higazî (Chakwatî fî-l-hubb, salû hamrat al-khaddayn) obéissent à cette règle. Par ce biais, on ne s'adresse pas directement à l'aimé(e), on se plaint plutôt à des tiers. Mais il y a de notables exceptions (arâka 'asiyyad-dam'). Parfois même, scellant leur passage dans le champ profane, des cheikhs enregistreront des qasîda-s " gharâmiyya » où l'être aimé est interpellé au féminin et où le vocabulaire ne laisse aucun doute sur la nature de l'amour envisagé, tel le grand munchid cheikh 'Ali Mahmûd (qasîda anâ minki dhû walah wa dhû achwâq), qui se voit désigné sous la triple étiquette de "al-mutrib al-qadir al-'ustâdh al-chaykh", titres connotant à la fois le religieux et le profane. 
13 Du point de vue de la loi religieuse (mais il faudrait ici instaurer une plus nette distinction entre les diverses écoles), les textes qui évoquent, le désir, la séparation, sont reconnus comme acceptables et ce thème apparaît comme largement dominant dans le dawr par exemple. Par contre, parler d'une joue, d'une taille (al-qudûd wa-lkhudûd) est reprochable (mais le cheikh Salâma Higâzî, on l'a vu, aborde en ces termes ce registre du corps). L'évocation du corps parle au corps, éveille la sensualité, les instincts (yuthîru-l-gharâ'iz). Voilà bien le point où se noue toute la question du licite et de l'illicite. Tout texte de bonne tenue littéraire est admis à partir du moment où rien en lui n'est susceptible d'éveiller les sens.

Mais c'est dans son esthétique et plus encore dans la conception du chant que la tradition de la nahda gomme les frontières. Le trait commun est l'improvisation générant le tarab. Comme le dit justement Christian Poché ${ }^{7}$ le tarab, tel que conçu par les grands de la nahda, est « un art qui sépare peu le sacré du profane : à cet égard, la qasîda de Salâma Higazî détermine moins une courbe qui annonce Umm Kulthûm qu'elle n'anticipe l'orientation suivie ultérieurement par le récitant de Coran 'Abd alBâsit 'Abd al-Samad ». Les mêmes codes régissent ici le wajd et le tarab (il n'est que d'écouter certains enregistrements "publics» du même 'Abd al-Bâsit - sourate 'âl 'imrân - pour s'en persuader : même utilisation des silences, même participation de l'auditoire).

15 Concernant ces faits, on pourrait tenter sans risque un parallèle avec d'autres traditions musicales d'essence religieuse trouvant leur prolongement dans le champ profane : le negro spiritual et la soul music. L'examen des biographies est à cet égard révélateur. Sans avoir qualité d'officiants, sans relever d'un quelconque ministère, un Ray Charles, un James Brown, un Otis Redding, une Aretha Franklin, étoiles scintillantes de la soul music, ne sont-ils pas issus du pur vivier religieux ? La louange du « Lord » n'at-elle pas façonné leur style et leur voix?

16 Il découlera de cette pratique du chant basé sur l'improvisation héritée de la psalmodie coranique que «la musique d'un compositeur n'est pas, avant la génération de Muhammad 'Abd al-Wahhâb, sacralisée au point que l'on doive la considérer comme une œuvre parfaite et finie $»^{8}$. Nous y reviendrons. Lorsque précisément 'Abd alWahhâb se mettra à créer des formes, plus perceptibles, plus individualisées, plus " figuratives ", on parlera à son propos de bid'a. Créer une telle forme, n'est-ce pas une bid' $a$ ? Certains auteurs arabes modernistes n'ont-ils pas pu dire en effet que la musique basée sur l'improvisation maqâmienne était « sans forme » ? L'opposition entre tatrîb et mîlûdî (mélodie) posée par d'autres ${ }^{9}$ ne trouverait-elle pas du même coup quelque pertinence? Qu'on s'entende bien, le dawr, le muwachchah, la qasida, sont des formes composées (quoiqu'à des degrés divers suivant les époques), mais c'est l'improvisation qui y prime, jetant l'auditeur dans un univers « systémique » qui est celui du maqâm. Ce que l'auditeur (initié) apprécie dans ce contexte est non seulement la prouesse vocale mais aussi la complexité d'un discours prouvant une maîtrise de ce système, sa capacité à s'en jouer (art de la modulation, de l'exploration des constellations modales, du respect des marâkiz, de la tension appelant la qafla). Or, avec le genre de musique qui s'installe quelques décennies plus tard, en particulier la taqtûqa, puis la voie inaugurée par Muhammad 'Abd al-Wahhâb, on entre dans un univers de la forme. N'est-ce pas là la marque du passage à la modernité ?

17 L'historiographie a dépeint al-Hamûlî comme un nationaliste soucieux d'affirmer le caractère de son pays. Tous ses biographes citent à plaisir l'anecdote fameuse selon 
laquelle il fut emprisonné à Istanbul pour avoir osé chanter le dawr 'echnâ w-chofnâ snîn, écrit à la suite de la révolution orabiste ('Isma'îl Sabrî Pacha/Muhammad 'Uthmân) et exprimant une critique voilée de la politique du sultan :

'echnâ w chofnâ sni / wa man 'âcha ichûf al-'agab

Charebnâ-s-sabr wa-l'anîn / ga'alnâhu le-rûh-e-nâ tarab

Keda-l'adl yâ munsifin

18 Cette composante nationaliste du fondateur de la musique égyptienne moderne contribuera à la naissance d'une histoire quelque peu mythifiée d'un 'Abduh al-Hâmûlî « libérant » la musique arabe de l'emprise de l'esthétique ottomane ${ }^{10}$ alors que chez des auteurs proches de la royauté-, tels Mahmûd 'Ahmad al-Hifnî, la "fusion » et le lien historique avec la musique turque sont toujours affirmés ${ }^{11}$. D'autres, après la révolution, prétextant dans la même ligne de pensée l'essence turque de la musique de la nahda, justifieront par ce biais la nécessité de se débarrasser de tout classicisme pour aller vers une musique moderne à caractère strictement national. Il y a là un forçage évident, la musique savante égyptienne de la nahda ne pouvant pas, on le comprend, être identifiée totalement dans son principe et son esthétique à la musique turque ${ }^{12}$. L'interprétation des rythmes nous en offre un exemple remarquable: ornementation d'un côté (actualisation des repères intermédiaires et tendance au déplacement), dépouillement de l'autre (énoncé linéaire et intériorisation des vides temporels). Enfin, des esprits plus nuancés et plus justes, tel Medhat 'Asem, sauront mieux définir le véritable rôle d'al-Hamûlî et de Muhammad 'Uthmân (Cf. infra p. 104).

De la rencontre avec cette musique turque, des formes anciennes et connues précédemment en Égypte telles le muwachchah, la qasîda et le dawr se trouveront enrichies et se fixeront dans des formes plus sophistiquées. De ces trois formes, c'est au dawr qu'il convient de s'attacher plus particulièrement car c'est lui qui, à travers les premiers enregistrements et les tournées des grands chanteurs égyptiens au Maghreb et au Machreq, impose leur voix dans une partie du monde arabe ; surtout, c'est autour de lui que s'effectue un premier remaniement de la langue des chansons. Cette question de la langue, bien évidemment, est ici essentielle.

La langue des premiers dawr-s est une langue composite mêlant artificiellement des tournures classiques au dialecte, aux fins, probablement, de faire accéder un genre d'origine populaire à un registre poétique plus noble. Pour cela, elle en emprunte les clichés, d'où une grande pauvreté des thèmes et une récurrence du même vocabulaire. C'est que le dawr est avant tout une forme improvisative où l'on se soucie peu de la qualité et de l'expressivité du texte ; l'expression, le sentiment intérieur devant passer par la voix du chanteur. Hormis les 'adwâr composés par le Cheikh al-Maslûb, offrant semble-t-il une plus grande unité linguistique, la langue du dawr ne craint pas et semble même cultiver les oppositions ('ashi't-e-hosnak; e'chaq el-khâles li-hobbak: bahr el-'ichq, fi char' min ; et surtout awân al-wasl).Parallèlement à ce genre à la langue non encore fixée (on parle à son propos d'« arabe moyen »), perdure tout un répertoire de chansons en langue très populaire, grivoises, dont 'Alî 'Atiyya s'indigne du fait qu'elles soient chantées devant les filles, les soeurs et les épouses ${ }^{13}$. Dans ce contexte, le besoin d'une nouvelle langue se fait sentir, plus unie au plan du registre linguistique et de plus haute tenue dans l'expression. Dès le début des années vingt, un poète se consacre à cette tâche, considéré comme un pôle de la nahda littéraire : Ahmad Râmî ${ }^{14}$.

21 Mais à qui revient la première impulsion? Dans l'une de ses dernières interviews accordée au Musawwar, Umm Kulthûm déclarait ${ }^{15}$ : 
"Je pense que ce qu'il y aurait de plus important à dire sur moi après ma mort est que j'ai fait passer le public de la médiocrité qu'il vivait dans le domaine de la chanson, avec des choses comme Erkhi-s-setâra elli fe-rêhna lahsan gerânnak tegrâhna ('Abd al-Latîf al-Bannâ) au niveau de Inna hâli fî hawâ-hâ 'ajabun (Râmî/Qasabgî) et de As-sabb tafdaho 'uyûno (Râmî/Abû al-'Ilâ Muhammad) ou des Rubâ'iyyât alKhayyâm (Râmî/ Sunbâtî). Ce qui m'a déterminée à me lancer dans ce combat est qu'un jour, à mon retour de Mansûra, ayant chanté la qasîda Subhâna man arsalahu rahmatan li-kulli man yasma', le public m'a sifflée et s'est mis à crier : "Nous voulons Hât al-ezâza wa 'od lâ'ebnî". Je n'en ai pas voulu au public qui s'habitue à ce qu'on lui donne, mais j'ai pensé qu'on pouvait l'acclimater à autre chose. Un jour, je dis à Râmî (l'action est située en 1922), "Le publie doit passer par étapes des chansons triviales qu'il écoute aux qasida-s et à la grande poésie. " Râmî me répond: "Mais justement, je vous ai écrit la qasîda Inna hâli fî hawâ-hâ 'ajabun" : J'ai dit: "Elle me paraît assez facile, je la chanterai, mais je préfèrerais que nous utilisions dans les paroles des chansons des choses simples et courantes que les gens peuvent comprendre sans peine". Il m'a répliqué: "Mais c'est exactement ce qu'ils entendent aujourd'hui !" J'ai dit: "Je veux faire un pas de plus, plus ambitieux, je veux une langue comme celle des journaux, comprise par tout le monde, qui ne soit ni vulgaire ni hermétique." »

Si l'on ne sait qui fut l'initiateur de cette "réforme », toujours est-il que la langue de Râmî obéit à ce souhait et qu'avant son premier zagal (poésie en arabe dialectal) pour Umm Kulthûm (Khâyef yekûn hobbak chafaqa 'alayya, 1924) il n'avait écrit qu'en arabe classique. Umm Kulthûm ne se séparera pas de Râmî pendant près de cinquante ans. Une des raisons du formidable succès hors d'Égypte des chansons d'Umm Kulthûm, écrit Frédéric Lagrange ${ }^{16}$, " est qu'elles sont écrites dans une langue claire qui ne fait appel aux dialectalismes que pour les outils du langage: les toi, moi, pourquoi, comment, où, quand, encore ». La langue de Râmî se situerait dans le diagramme proposé par Sa'îd Badawî et Martin Hinds ${ }^{17}$ dans le registre de la 'âmmiyyat almuthaqqafin (dialecte des intellectuels). C'est une langue moyenne qui, si elle reflète la même mixité que le dawr, substitue aux structures d'opposition une structure plus distributive (cadre grammatical dialectal, vocabulaire classique. Exemples: Lêh telawi'înî; Fâker lammâ kont-e-gambî). On voit ici à l'oeuvre un travail de rénovation de l'écriture qui a contribué à sa manière au nivellement de la fushâ (arabe classique) et du dialecte, à l'unification des niveaux de langue caractéristique de l'époque moderne. Estce en ce sens qu'Umm Kulthûm parlait de « langue des journaux »?

\section{Déclin de la tradition « classique »}

23 La brillante renaissance du chant arabe décrite au début de cet article, art savant ayant su épurer ses formes pour parvenir à un haut degré de tarab, amorce un recul au cours de la première guerre mondiale et disparaît brutalement au début des années 30 . À ce phénomène préside un ensemble de facteurs aisément repérables pouvant permettre d'avancer un embryon d'explication.

\section{Le disque}

(Les données historiques concernant l'histoire du disque m'ont été aimablement fournies par F. Lagrange.) 

du 78 tours que la limite de trois minutes pour une face, s'avèrent inadaptés à une musique basée sur l'improvisation où le chanteur doit disposer d'une durée au moins égale à 15 minutes pour développer son discours. Il faut donc tronçonner ces pièces et les distribuer sur plusieurs faces (jusqu'à cinq). Cet inconvénient est poussé à l'extrême et avec des conséquences graves d'ans le cas des grandes suites. Yurgen Eisner a montré ${ }^{18}$ comment le découpage de la nûba maghrébine, dans les enregistrements du Congrès du Caire, a pu conduire à des transformations de la tradition, notamment par les interruptions brutales donnant une idée fausse de la qafla originelle et par la suppression des parties indépendantes et des figures répétitives consubstantielles au travail de création formelle. Dans une première étape donc (jusqu'à 1915), le disque tente de s'adapter à la musique appréciée par un petit public d'esthètes, les artistes se pliant aux exigences du support. Mais peu à peu, l'industrie phonographique gouvernant le marché, le disque va générer sa propre esthétique. La compagnie demande des produits faits pour le disque. Le problème n'est plus de faire entrer de force les morceaux improvisatifs dans le cadre étroit du 78 tours, mais de demander aux compositeurs des morceaux créés spécialement pour lui. Ceci passe par une quasisuppression de l'improvisation. La forme qui se prête le mieux à cette exigence est la taqtûqa aux couplets et aux refrains fixés et entièrement composés, qui connaît son âge d'or dans les années vingt. Une plus grande richesse des développements modaux remplace l'invention de l'artiste. À un développement interne des cellules du maqâm se substitue une juxtaposition de maqâm-s. À la fin des années trente, de rares artistes comme Sâlih 'Abd al-Hayy défendent encore l'art traditionnel mais, boudés des maisons de disques, ils ne sont plus enregistrés que par la radio qui d'ailleurs ne les diffuse jamais ${ }^{19}$.

Autre élément décisif, à partir de 1927, les compagnies d'enregistrement font figurer auprès des titres inscrits à leur catalogue et sur la vignette des disques la mention «musajjal », terme à comprendre dans le sens de «droit réservé ». La compagnie a acheté, souvent pour une somme minime ${ }^{20}$, la composition de tel morceau et s'en réserve le droit d'exploitation exclusif. Ce phénomène a une influence considérable sur les anciennes pratiques. Comme on l'a dit, à l'époque des débuts de la nahda, la figure du compositeur n'était pas sacro-sainte. On considérait que telle composition appartenait à la communauté des interprètes fondés à y inscrire leur empreinte. On cite souvent l'anecdote de 'Abduh al-Hamûlî qui, chargé d'interpréter le dawr Add-e-mâ ahebbak za'lân mennakde Muhammad 'Uthmân dans le contexte joyeux d'un mariage, en avait changé le mode originel, passant - à la grande admiration du compositeur luimême ! - du sabâ au nahawand. Ce genre de pratique est nécessaire à la culture d'une tradition, à l'épanouissement d'un classicisme. Le jazz a pu naître et évoluer grâce à la jam-session au cours de laquelle le répertoire est travaillé comme une matière à revisiter sans cesse et où les musiciens créent leur technique et leur discours improvisatif. En fait, ces chanteurs-compositeurs du début du siècle sont des "classiques " au vrai sens du terme, dans le sens où Jorge Luis Borges a parlé de la littérature : «Si la thèse selon laquelle tous les auteurs sont un seul auteur est vraie [...], le panthéiste qui affirme que la pluralité des auteurs est une illusion trouve un appui inespéré chez le classique pour qui cette pluralité importe fort peu. Pour les esprits classiques, c'est la littérature qui est l'essentiel, non les individus. ${ }^{21}$ Il conviendrait donc d'opposer à une acception musicologique de la notion de "classicisme", simple étiquette commerciale (la musique classique, le jazz, le « musette ») une autre, plus « ontologique ». 

La naissance du roman arabe marquerait à ce titre une rupture, peut-être comparable à celle installée par Muhammad 'Abd al-Wahhâb et qui semble consacrer l'importance du compositeur et de «l'œuvre» musicale en tant que forme individualisée. Ce refus ou, tout au moins, cet aspect secondaire de l'individualité, trouve aussi sa pleine affirmation dans le cadre de la musique et du chant tel qu'il est pratiqué et conçu au début de la nahda. Destinée par essence à subir l'empreinte de l'improvisation, laquelle trouve son origine et sa technique dans la psalmodie coranique, la notion de composition reste très vague, voire marginale, jusqu'à Muhammad 'Abd al-Wahhâb. La grande révolution introduite par le disque va être cette coupure sémantique : ghinâ'l ughniyya, d'un côté, l'art du chant, en tant qu'essence indivise, de l'autre l'ughniyya composée, autonome et tombant sous le «droit réservé ».

ces aspects techniques et commerciaux ont été décisifs, un certain contexte historique et socio-politique est à prendre en compte. La révolution de 1919 nous paraît déterminante, qui marque l'avènement d'une bourgeoisie éprise de modernité et désireuse de se démarquer des élites turcophiles. Déjà, l'issue de la première guerre mondiale consacre la fin du parti turc de Mustapha Kâmel. La lutte pour l'indépendance menée par Sa'd Zaghlûl Pacha, la révolution qui la couronne violemment, inaugurent une ère nouvelle. Le nationalisme va de pair avec l'exigence d'un "modèle national » de chant, l'art classique étant à tort assimilé à la période ottomane. Cette conception aura la vie dure et reparaîtra comme on le verra après la révolution de 1952. De plus, il ne fait aucun doute que les goûts ont changé. On comprend qu'avec l'élargissement du public, les anciennes formes improvisatives, demandant une écoute initiée, soient délaissées au profit de formes privilégiant une mélodie facile à retenir. Cette exigence impose une mutation: on passe du tatrîb àla mîlûdî. On entre dans une conception moderne du temps. Au temps long, à développement linéaire du dawr, se substitue le temps court, segmenté, des formes composées.

Le disque, à son tour, sera évincé par l'apparition du cinéma parlant (1932) et de la radio d'État (1934). Cette fois-ci, ce sont le cinéma et la radio qui fixent la norme en matière de chant. Le disque ne retrouvera une vitalité qu'au début des années 50 avec le microsillon 33 et 45 tours avant de disparaitre à nouveau de manière quasi-complète en Égypte (et dans une bonne partie du monde arabe) au début des années 80. Commence alors le règne absolu de la cassette, cette dernière permettant un piratage plus facile et un matériel de lecture plus léger. Aujourd'hui, toutes les usines de pressage de disques ont fermé leurs portes en Égypte. Le disque est un produit « fini » ${ }^{22}$.

\section{La naissance de la scène}

L'art savant que nous venons de décrire est l'art d'une élite. L'espace dans lequel il est pratiqué est un espace fermé, fréquenté par un public de connaisseurs. Les grands chanteurs se produisent, comme on l'a vu, à la cour khédiviale ou au cours de soirées privées organisées par les riches familles citadines. Or, dans la conservation d'une tradition, un rôle fondamental doit être reconnu aux récepteurs. Cette situation prévaut dans tous les groupes humains où la musique est dotée d'une fonction sociale précise. John Blacking ${ }^{23}$ a montré comment, dans la petite société des Vendas du nordTransvaal, chassés dans les montagnes par les colons blancs, chaque élément du groupe est capable de reprendre tel tambourineur faisant une faute de rythme au cours d'un

Égypte/Monde arabe, 7 | 1991 
rituel. Ces maitres percussionnistes ne sont que des individus comme les autres n'ayant fait que développer certaines facultés en sommeil chez leurs congénères. Le rôle des récepteurs est fondamental dans le maintien de la qualité et de l'authenticité d'une tradition. Poussant le raisonnement à l'extrême, Blacking suggère que la musique de Bach ne serait pas ce qu'elle est sans le rôle de son public. Or, la naissance de la scène fait éclater cette relation d'interdépendance dans la mesure où elle installe une distance, voire une coupure, entre le public et l'artiste.

31 À cela s'ajoute le langage introduit par le théâtre et le nouveau type de chanson qu'il demande. Dès le début, il s'avère impossible de faire admettre au public une pièce où la chanson n'a pas sa place (on sait que Salâma Higâzî avait dû bien vite renoncer à sa tentative d'imposer la tragédie reposant sur le texte seul). Cette nécessité, pour le théâtre, d'intégrer le chant, se retrouvera plus tard au cinéma : un journaliste pourra dire de façon plaisante, à la sortie du premier film égyptien parlant - Unchûdat al-fu'âd, 1932: «Si le cinéma, en Égypte, n'avait pas été musical, c'est à dire prétexte à chansons, il serait certainement resté muet! ». D'où l'importance de la chanson, mais dans un contexte nouveau qui nécessite des formes nouvelles. Disons simplement que le théâtre demande une plus grande expressivité ou, si l'on préfère, plus de réalisme. Une expressivité au service d'un texte précis collant à une intrigue et au développement d'un récit quand le chant traditionnel faisait passer l'expressivité par la virtuosité vocale sur un texte souvent pauvre et bourré de clichés (aussi bien dawr que néo-muwachchah), par conséquent "décontextualisé ». C'est pourquoi Salâma Higazî chantant au début ses qasîda-s en intermède entre les scènes sera bientôt amené à développer un type de chant servant davantage le récit. La forme qui va se développer au théâtre est un texte narrant un récit personnel, intérieur, en rapport direct avec la pièce. C'est l'essor du mûnûlûg ou du diâlûg. Au niveau de la musique et de l'orchestration, cette même exigence d'expressivité sera décisive en ce sens qu'elle précipitera, notamment sous l'influence de Sayyid Darwîch, l'adoption d'une écriture musicale européanisée et privilégiant l'utilisation d'instruments européens recherchés pour leur plus grand pouvoir d'émotion. L'exigence deviendra alors celle d'une musique «descriptive » (taswîriyya)ou mieux, «expressive» (ta'bîriyya). Dans cette quête, on le sait, l'esprit de la révolution de 1919 est déterminant. Or, les modernistes déclarent unanimement le takht et ses instruments comme impropres à exprimer des sentiments forts. Wadî' Sabra affirme (propos rapportés par al-Chujjâ'î) que «la musique, privée de l'harmonie, ne donne à l'auditeur que le tarab». On sent bien que ce besoin d'occidentalisation de la musique est d'abord commandé par le théâtre, ceci, certainement, sous l'influence de l'opéra. En fait, c'est tout le rapport musique-paroles qui est ici en cause. Medhat 'Asem résume bien le propos ${ }^{24}$ : «Bien que grandement influencée par le style du chant turc, l'école de Muhammad 'Uthmân et de 'Abduh alHamûlî a créé un caractère égyptien propre, qui a une saveur originale, distincte, même s'il emprunte la même voie esthétique - celle du tatrîb - dominée par des figures musicales douces, mélodieuses, où le mot est soumis à la mélodie et non pas le contraire comme cela devrait être. Puis est venu le cheikh Salâma Higazî qui a donné au chant une tonalité théâtrale qui s'affranchit de la monotonie du rythme et essaye d'exprimer le sens des mots dans un style naïf, lequel ne pouvait que rester soumis à cette "douce" mélodie ou à ce tatrîb émouvant [...]. Enfin est venu Sayyid Darwîch qui a apporté une révolution dans le monde du chant en le faisant passer d'un art visant au tatrîb [...]à un art ayant pour but l'expression dramatique, de sorte que la mélodie soit soumise au mot, en illustre tout le sens ». 

partir des années trente sous l'influence conjuguée du théâtre et des "modernistes » ('Abd al-Wahhâb, Sayyid Darwîch, et dans une certaine mesure Zakariyâ Ahmad) participaient chez ces derniers d'une idéologie. Ces mukhadramûn (à cheval sur deux générations, deux courants, etc.), formés à l'école ancienne, auraient délibérément cassé cette tradition jugée par eux dépassée et ne collant plus à l'idéal de modernité prôné par les intellectuels. Ces auteurs n'ont sans doute pas tort. Notons toutefois que l'idéologie nous paraît plus présente, affirmée en tout cas de manière plus féroce chez les partisans du qadîm (ancien). Ceci est patent dans des oeuvres de conservateurs convaincus comme Muhammad al-Khula'î, dont le Kitâb al-mûsîqî al-Charqî paraît en 1906 et qui s'inquiète (déjà !) de la dégradation du répertoire et de la pratique musicale. Quelques décennies plus tard (1949) paraît un opuscule significatif, dû à Muhammad Abu al-Khidr Mansî ${ }^{25}$, dans lequel les « modernistes » 'Abd al-Wahhâb et Umm Kulthûm sont vilipendés et accusés d'avoir cassé la tradition aux fins de s'enrichir. Il est notable que l'écriture de ces ouvrages sacrifie à un style apparenté à la plus belle et conventionnelle prose rimée. À chaque fois qu'une tradition est menacée on observe ce retour revanchard de l'esthétique classique qui s'illustre dans cette forme de pensée et d'écriture cycliques.

Peut-être, outre cette idéologie des novateurs, verrions-nous pour notre part, avec plus de certitude, une "stratégie de distinction ». Lorsqu'une tradition s'effrite, l'on doit voir si l'assise sociale de sa reproduction est suffisamment large ou restreinte (l'essor d'une bourgeoisie moderniste lassée de l'esthétique turque succède à la révolution de 1919 et il est vrai que le recul des genres improvisatifs anciens, tels le dawr, procède d'une désaffection du public qui souhaite des airs plus faciles à retenir et à chanter). Il faut aussi dans ce contexte considérer les enjeux des éventuels candidats à la reprise. Qu'est-ce qui, pour Muhammad 'Abd al-Wahhâb, à la fin des années vingt, est le plus payant: s'identifier à l'image du cheikh ou à celle de l'effendi, symbole de cette bourgeoisie montante qui défie l'aristocratie? On pourrait traduire cette proposition en termes vestimentaires : faut-il miser sur le turban ou bien sur le tarbouche? Toute une littérature reflète ce dilemme, pour ne pas dire ce combat. Rappelons-nous, dans Bayn al-qasrayn (Impasse des deux palais), le vieux cheikh Mitwallî 'Abd al-Samad félicitant son protégé Ahmad 'Abd al-Gawwâd d'avoir gardé les traditions de son père, sauf le turban qu'il a troqué contre le tarbouche. Dans le début des années 30, la presse libérale ironise d'une manière à peine voilée sur cet auguste couvre-chef. La revue Al-râdiû offre des titres du genre : «Où est donc le turban égyptien qui bat le record d'élégance, de finesse et de distinction? " (ayna hiya-l-'imma al-masriyya-llatî tadrîb al-raqm al-qiyâsî fí-zzarf wa-l-riqqa wa-l-'adab ?) ${ }^{26}$, citant la mésaventure du cheikh 'Abd al-'Azîz al-Bichrî qui, se rendant bras-dessus bras-dessous avec son ami Hâfez 'Ibrâhîm à l'hôtel Continental, propulsé en entrant par le tourniquet, se prend les pieds dans le tapis et s'écrase face contre terre. Pour tromper l'attitude moqueuse des spectateurs, le cheikh ferme les yeux et fait croire qu'il est aveugle, gagnant la compassion gênée des moqueurs. Voilà bien, nous dit l'auteur en conclusion, « toute la finesse du turban égyptien qui bat tous les records d'élégance et de raffinement ! » Pour mémoire, un grand projet économique de l'époque, baptisé machrû' al-irch, destiné à fouetter l'esprit d'entreprise de la jeunesse, aboutira à la construction d'une usine de tarbouches dont une rue du Caire a gardé le nom (Ch. masna' al-tarâbîch). 'Imâma et tarbûch (tarbouche, fez) renvoient désormais à des genres différents, y compris en matière de musique. De là à poser la double équation : tatrib (maqâm) = turban/mîlûdî = tarbouche, il n'y a qu'un pas que le 
critique 'Anwar 'Abd Allah franchira dans un article célèbre intitulé : «Abd al-Wahhâb, lahnun khala'a al- 'imâma wa labisa al-qubba'a » (" 'Abd al-Wahhâb, une musique qui a ôté le turban et coiffé le chapeau »)27.

Les changements apportés par 'Abd al-Wahhâb vers 1928 (takht étoffé d'instruments occidentaux - violoncelle et contrebasse) sur le conseil présumé d'Ahmad Chawqî (fî-llêl lammâ khilî), puis dès les premiers films, Al-warda al-baydâ' (1933), Dumû' al-hubb (tangos et rumbas mêlés au chant oriental), enfin l'orchestration (Anâ wa-l-'adhâb wa hawâk) sont d'ailleurs nommément qualifiés de bid'a, terme qui deviendra classique dans la presse sous la forme associative "bid'at 'Abd al-Wahhâb». La référence au religieux, à la 'imma, est consommée. Ayant grandi dans une famille portant gubba (ou gibba, longue robe ouverte sur le devant) et 'imâma, le jeune 'Abd al-Wahhâb manifeste très tôt sa désaffection pour la destinée de mu'adhdhin (muezzin) qui lui est prescrite, ce qui lui vaut un jour une humiliation publique lorsque son frère, le cheikh Hasan, pour le ramener dans la voie de la tradition, le tire les mains liées du quartier d'al-Husayn jusqu'à Bâb al-Cha'riyya, ensanglantant son corps et son orgueil à la face du monde. De là l'empressement du jeune homme à ôter la 'imâma non seulement de lui-même mais de la musique, l'oreille tournée vers les innovations apportées par Sayyid Darwîch.

Nous n'avons pas envisagé, parmi ces facteurs de rapide déclin du classicisme égyptien, la simple éventualité d'une tradition épuisée. Ne peut-on pas considérer - simple hypothèse de travail! - que les quelque soixante-dix années au long desquelles se développe ce dernier est une période à la fois courte et suffisamment longue pour conduire à une certaine forme d'épuisement, de tarissement. Ne peut-on pas considérer que la lignée des grands chanteurs avait épuisé les ressources du maqâm et les avait menées à leur ultime aboutissement, ou plutôt, si l'on considère que l'univers maqâmien est inépuisable, ces chanteurs ne l'avaient-ils pas épuisé justement parce qu'il était inépuisable ? Le caractère nécessairement versatile des goûts pouvait-il se suffire de cette infinité? L'art d'une Umm Kulthûm dans ses enregistrements antérieurs aux années 30 n'apparaît-il pas comme un art achevé, porté à sa plus sublime altitude? On pense ici à d'autres traditions, tout aussi solides, senties comme épuisées par leurs plus géniaux continuateurs. On pense à Charlie Parker et à la tradition du blues, forme classique dont la durée d'élaboration est comparable à celle $\mathrm{du}$ " classicisme » égyptien. La biographie de Ross Russel, « Bird », nous dépeint vers sa fin un Charlie Parker ayant le sentiment d'avoir mené le blues à ses ultimes conséquences, tentant, en quête d'une inspiration nouvelle, de timides et émouvantes approches auprès des compositeurs modernes, Varèse, Stravinsky. John Coltrane reprendra le flambeau, cultivant les enseignements du maître au moyen d'une technique géniale, mais les surpassant peu dans le discours. Cette étape durera peu de temps. Bientôt l'expérience modale viendra offrir une issue à ce qui était peut-être une impasse.

\section{Deuxième jalon pour une chronologie de la réforme musicale en Égypte}

\section{La question du système tonal arabe : le Congrès du Caire de 1932}

C'est dans le contexte, évoqué plus haut, d'une tradition classique en situation de faillite et du sentiment général que la musique arabe traverse une crise due à 
l'envahissement de la musique occidentale, que le Congrès du Caire a été convoqué à la demande, dit-on officiellement, de S.M. le roi Fouad Ier, protecteur des Arts et Lettres.

À l'époque du Congrès, la musique occidentale est fortement enracinée dans le paysage artistique cairote. Citons pour mémoire, entre autres marques de cette présence :

1. De 1824 à 1834, fondation par Muhammad 'Alî de cinq écoles de musique militaire au Caire, encadrées par des Allemands et des Français.

2. 1869, inauguration de l'Opéra du Caire qui, dans ses saisons annuelles, accueille un grand nombre d'artistes italiens, certains résidant au Caire.

3. Dès le milieu du XIX siècle, quatre instituts de musique européenne existent au Caire, dirigés par des Italiens.

4. Commanditée par le Congrès, une étude statistique sur l'enseignement musical en Égypte révèle une désaffection, par les Égyptiens, de la musique arabe au profit de la musique occidentale ${ }^{28}$.

5. Dans un numéro de L'Epoque Moderne datant de 1931, traitant de la musique populaire égyptienne, un certain Vampierre remarque l'influence considérable du café-concert et des chansons légères parisiennes sur le répertoire des chansons. Il note que certaines familles musulmanes font défiler pendant leurs enterrements des orchestres jouant des valses lentes qui menacent la tradition des pleureuses.

6. J.-F. Belleface a bien montré29 que dans les années 1925 , en matière de spectacle, Le Caire n'est peut-être pas très différent des grandes capitales européennes.

Cette présence de la musique occidentale a eu une influence indéniable sur certains aspects de la musique en Égypte. À la veille du Congrès, Bêla Bartok avait pressenti l'état de dégradation de la musique égyptienne, déclarant: "La musique de divertissement européenne fait sentir ici aussi son effet ravageur. $»^{30}$

Considérant l'attrait que la musique occidentale exerce sur les jeunes compositeurs, les représentants du qadim en concluent que la musique arabe traditionnelle est à réformer pour lui faire retrouver toute sa force d'expressivité. De plus, observant le manque d'unité qui affecte l'échelle musicale d'un pays arabe à l'autre, ils en concluent remède suprême à leurs yeux - à la nécessité d'arriver à un système valable pour l'ensemble du monde arabe.

Définissons ce Congrès en un mot: une entreprise réformiste. Réformiste au sens le plus courant de ce terme dans le contexte social et religieux et visant aux mêmes buts : adapter la tradition à la modernité sans altérer son essence et, point important ici, en mettant à profit les méthodes scientifiques de l'Occident. On voit d'emblée la différence avec la problématique générale de la première nahda des grands chanteurscompositeurs du milieu du XIX ${ }^{e}$ siècle. Alors que ceux-ci recomposaient les éléments d'une tradition régionale à cheval sur plusieurs cultures ethniques mais relevant d'un vaste domaine où les systèmes modal et rythmique présentent des caractéristiques communes, les réformateurs de 1932 croient pouvoir impulser une force nouvelle à la musique arabe en " unifiant » son système modal et surtout, en affinant les instruments de sa notation. D'où un effort d'adaptation de l'écriture musicale occidentale au système tonal arabe. Ce qui ne va pas sans problèmes, vu l'instabilité des microintervalles tels qu'utilisés dans la pratique et l'impossibilité de les réduire à des unités du type demi-bémol par exemple.

L'optique du Congrès se situe à un double plan : modernisation et conservation. Citons pour mémoire ce passage de la déclaration inaugurale du Ministre de l'Instruction 
publique, Président du Congrès, Muhammad Hilmî Pacha 'Isâ: "La mission de ce Congrès est d'organiser la musique arabe sur une base stable, scientifique et technique dont conviendront tous les pays arabes, d'étudier les moyens permettant à la musique arabe d'évoluer [...]. Ces buts, il fallait s'employer à les atteindre. Il fallait se hâter de conserver les chants et les mélodies de toutes sortes pour n'avoir plus à les recueillir par la seule voie de la tradition, car c'est un précieux héritage à enregistrer. $»^{31} \mathrm{Ou}$ bien : "Quelle serait la meilleure voie à suivre pour assurer le développement de la musique arabe et lui permettre de répondre à toutes les exigences de la musique en général, tout en gardant son caractère distinctif ? $»^{32}$.

Ainsi, la musique arabe est jugée comme une musique dans l'impasse, incapable d'évoluer et vouée à la disparition faute d'une base théorique stable qui en fixerait les règles. Cette situation est tout entière imputée au caractère dominant de la pratique musicale uniquement appuyée sur la tradition orale. De là l'exigence d'une rationalité. Au plan de l'histoire des idées, on pourrait dire que ce Congrès marque une tentative de revanche du rationalisme sur l'empirisme. Cette problématique est reflétée par le débat central du Congrès : la fixation de l'échelle musicale et des intervalles. Or, ce débat, d'apparence technique, recouvre des visées idéologiques fondamentales.

\section{Pratique orale et théorie : la « feuille » et le papier}

Le but est d'en finir avec l'aspect pratique et non théorisé de la musique arabe, de reconstruire le lien jadis existant - tel qu'il apparait dans les manuscrits - entre théorie et pratique, la première justifiant la seconde. Il faut imposer un système "scientifique ». Cette volonté repose peut-être d'ailleurs sur un complexe vis-à-vis de l'Occident. Muhammad 'Abd al-Wahhâb ne déclare-t-il pas, peu après la tenue du Congrès : «La fixation de l'échelle arabe ('igrâr al-sullam)nous permettrait entre autres de pouvoir répondre aux Européens lorsqu'ils nous posent la question embarrassante : sur quoi repose votre système tonal ? $»^{33}$.

En vérité, ce Congrès a vu coexister deux tendances :

Les «réformateurs", pour la plupart membres de l'Institut de Musique Orientale, ceux-ci considérant qu'il est impossible de toucher au système tonal égyptien et insistant sur la nécessité d'unifier tout au plus la dénomination des intervalles entre les divers pays arabes.

Les "modernistes", désireux de moderniser à tout prix la musique arabe afin de l'amener au rang de la musique occidentale, quitte à adopter une partie de son système et de ses instruments (piano, violoncelle, contrebasse). Ces derniers, dont les plus convaincus sont des facteurs de pianos tels Nagîb Nahhâs, Emile 'Ariyân, Wadî' Sabra, reprenant sans la nommer la théorie avancée vers 1850 par le SyroLibanais Mikhâ'îl Muchâqa, s'acharneront à démontrer - en dépit des évidences que l'échelle pratiquée en Égypte est identique à l'échelle tempérée divisée en 24 quarts de ton égaux. Pourquoi?

1. Avec cette échelle, on a un système unifié, valable pour tout le monde arabe et qui réduit les différences observées dans la pratique, d'un pays à l'autre. On a donc ici un souci d'arabité plutôt que d'affirmation d'une centralité égyptienne. D'ailleurs, cette conception n'est pas défendue que par les seuls Égyptiens (cf. le Libanais Wadî' Sabra).

2. On peut bâtir une politique cohérente de l'enseignement qui puisse donner lieu à la composition de manuels scolaires (on part du principe que les élèves sont perdus avec le système considéré comme totalement empirique des musiciens professionnels). On notera l'importance toute particulière donnée à l'enseignement par les membres du Congrès, toutes tendances confondues, comme moyen de régénérer la musique arabe. L'une des 
recommandations adoptées visera à instituer un examen auquel seraient soumis compositeurs et instrumentistes et sans l'obtention duquel ils ne pourraient exercer leur métier (réinstitutionnalisation du tahzîm de l'époque de la nahda).Cette proposition reviendra sans cesse ultérieurement.

3. Avec une échelle de 24 quarts de ton égaux, on peut introduire ou imposer les instruments à tons fixes (piano, cuivres), transposer les modes contenant la tierce neutre sur n'importe quel degré, faire une orchestration et, surtout, développer une harmonie qui fera la musique arabe de demain. En effet les théoriciens modernistes trahissent une pensée participant d'un certain darwinisme culturel en vertu duquel la musique arabe serait une branche caduque de l'arbre de l'évolution musicale qui culmine avec l'harmonie européenne, harmonie considérée par eux comme une sorte de passeport vers l'universalisme musical auquel ils aspirent, et l'on retrouve dans les déclarations de nombre d'entre eux l'idée selon laquelle une musique sans harmonie est une musique morte.

Les réformateurs sont fermement appuyés par les délégations étrangères composées d'orientalistes et de musicologues. 'Alî Jihâd Râcy ${ }^{34}$ a montré l'influence de l'idéologie des musicologues comparatistes de l'école de Berlin dans les critères retenus pour l'enregistrement des prestations des orchestres invités. Ce parti pris conservateur est aussi patent dans le choix de l'iconographie du Recueil officiel, laquelle élimine la floraison d'instruments originaux, «non traditionnels ", présentés au Congrès. Mais si l'on veut prendre toute la mesure de l'idéologie qui sous-tend cette manifestation, c'est la discussion portant sur la définition de l'échelle musicale qu'il faut considérer. Cette discussion a mobilisé le gros des énergies et constitue l'épine dorsale de ce Congrès. Nombre des décisions des autres commissions désignées en dépendent: commission des modes, des instruments de musique et de renseignement.

Pour répondre à la question fondamentale posée par le Congrès : "Si l'octave était partagée en 24 intervalles égaux résultant d'un rapport constant, la sonorité des maqamates en serait-elle altérée au point que ces modes perdraient leur caractère propre ?", on a procédé de la façon suivante : le qânûn (cithare), choisi en fonction de caractéristiques organologiques évidentes comme instrument étalon, a été accordé sur la gamme tempérée (la liste des longueurs de cordes correspondant aux intervalles principaux de l'échelle arabe, telle que définie par les musiciens, avait été préalablement établie). Les intervalles logarythmiques étaient fournis par un sonomètre. Pendant cet accord, les «arbitres » musiciens restaient hors de la salle. Dans une ambiance très "laboratoire ", avec ses savants en blouse blanche d'un côté, ses cobayes de l'autre, on introduisait ensuite ces derniers (les musiciens praticiens) séparément. On leur jouait la gamme et une phrase musicale. Ils trouvèrent cette musique " non conforme à la musique égyptienne ».

La sous-commission procéda ensuite à plusieurs essais pour la fixation des intervalles du mode rast tel qu'il avait été accordé par Muhammad Rida Bey. On obtenait une série de chiffres représentant des longueurs de corde : 


$\begin{array}{lll}\text { Do } & \text { rast } & 100 \\ \text { Ré } & \text { dôka } & 89,10 \\ \text { Mi bémol } & \text { sîkâ } & 81,75 \\ \text { Fa } & \text { jehárkần } & 75 \\ \text { Sol } & \text { nawà } & 66,66 \\ \text { La } & \text { husseiñi } & 59,40 \\ \text { Si bémol } & \text { tirâq } & 54,50\end{array}$

Les musiciens donnaient leur avis sur la parfaite égalité du son du qânûn et du sonomètre. Faisant établir les longueurs de cordes théoriques pour les notes de ce mode d'après la gamme tempérée de 24 quarts de ton, on obtenait des résultats identiques à quelques millimètres près. On fit une contre-expérience consistant à accorder le qânûn sur la gamme rast d'après les sons donnés par le sonomètre sur la base de l'échelle tempérée divisée en 24 quarts de ton égaux. Chacun des musiciens fut invité un par un à donner son avis. Les impressions, ainsi qu'il ressort des procèsverbaux du Recueil du Congrès, furent très dissemblables/Les " rationalistes ", tels Emile 'Ariyân ou Mansûr'Awad, tirèrent argument de ces divergences d'appréciation entre les musiciens pour prouver que leur connaissance de la musique n'était pas "scientifique », ravalant, en vertu de la distinction implicite mûsîqî l 'âlâtî (musicien/ musicien populaire) les grands instrumentistes de l'époque, tels Sâmî al-Chawwâ, au rang des seconds, le mûsîqî digne de ce nom restant pour eux à construire.

D'autres types d'expériences furent menées. Le qânûn fut accordé, selon les directives des musiciens, sur le mode nahawand. Le sonomètre donna les longueurs de corde suivantes :

$\begin{array}{lll}\text { Mi bémol } & \text { kươ } & 84,45 \\ \text { La bémol } & \text { hisâr } & 63,10 \\ \text { Si bémol } & \text { 'ajam } & 55,80\end{array}$

Puis on accorda le qânûn sur le mode hijâz où l'on obtint ces résultats :

\section{La bémol \\ Si bécarre \\ Mi bémol}

hisâr

nîn mâthur

kurd
62,10

53,20

83,80

Il en résultait que les degrés kurd et hisâr ne pouvaient être considérés comme des valeurs fixes, différant (en termes de longueur de corde et donc de hauteur) suivant leur environnement modal. Les «rationalistes» disaient de ces gammes qu'elles n'étaient «pas scientifiques » ou encore «non musicales ». On perçoit d'ailleurs, tout au long des procès-verbaux de séance, face au refus du système tempéré par les musiciens professionnels, l'exaspération des modernistes, peu enclins à penser en termes de richesse d'une tradition orale mais plutôt soucieux de logique et de conceptualisation. On pense ici à Platon, stigmatisant dans la «République » les subtilités excessives de ces mêmes musiciens professionnels qu'il traite de «tirailleurs de cordes $»$. 
52 À l'issue de ces débats, les réformateurs, fermement appuyés par les savants européens, l'ont emporté. Au Congrès certes, mais pas devant l'histoire. Dans la pratique (toujours elle!), l'avenir allait imposer un nivellement du système tonal, matérialisé par une simplification des intervalles et rejoignant sensiblement la notion d'échelle tempérée de 24 quarts de ton. Cette normalisation a d'abord affecté les modes renfermant la seconde neutre où le «quart de ton» a été abaissé (certains disent «ramolli»), par rapport à sa hauteur du début du siècle. Ainsi le sîkâ, revêtant normalement (mais il y a de multiples configurations suivant les régions) des hauteurs différentes dans les tétracordes sîkâ, rast et bayâtî, est "normalisé » par l'utilisation d'une seule note. On joue donc aujourd'hui en Égypte, conventionnellement, un seul mi demi-bémol pour les maqâm-s rast, sîkâ et bayâtî. Cette simplification des intervalles a aussi affecté certains genres dits chromatiques (élargissement de la seconde augmentée). Cette "normalisation» a été précipitée par l'utilisation d'instruments à tons fixes, notamment la guitare refrettée et le qanûn. Ce dernier, dépourvu de clapets ('urâbât) au début du siècle, a été «fretté » vers 1920 et refretté depuis si bien que n'offrant plus dans sa facture actuelle une division du ton permettant la différenciation entre les divers types de sîkâ ou la réalisation de la deuxième partie de la seconde augmentée du hijâz avec son fa-dièse légèrement rabaissé, intervalle spécifique qui avait fait dire à Wadî' Sabrâ, au Congrès du Caire, que cette gamme (hijâz) n'était " pas logique ». Pour ce sîkâ, pierre d'achoppement du système tonal arabe et dont la variabilité d'un pays arabe à l'autre avait motivé la réflexion du Congrès sur l'unification, l'Égypte a trouvé «sa » solution. Mais une comparaison avec la situation actuelle en Irak ou en Syrie révèlerait sans doute que le sîkâ « idéal » des congressistes n'a pas encore vu le jour. En 1932, le Congrès n'a pu imposer la division de l'échelle en 24 quarts de ton égaux car le poids de la pratique l'en a empêché, une pratique alors essentiellement orale et qui privilégiait une coloration beaucoup plus fine de l'échelle tonale, personnalisant certains intervalles dans tel maqâm pour mieux en exprimer l'ethos. L'oreille s'en estelle appauvrie ? À-t-on perdu certains états du sentiment musical ? Ceci ne fait aucun doute.

On est frappé, à la lecture de la presse cairote de 1932, par la violence des attaques portées contre le Congrès et plus encore l'Institut de Musique Orientale ${ }^{35}$. C'est tout un contexte qui est visé. Pour de nombreux esprits, l'Institut demeure un symbole du conservatisme des Beys et des Pachas. Ce n'est pas un hasard si le ministre de l'Instruction publique, Hilmî Pacha 'sâ, président du Congrès, ridiculisé dans toute la presse libérale pour vouloir aller contre le changement naturel des traditions, est félicité dans la revue al-Manâr ${ }^{36}$ comme l'homme le plus respectable. N'est-il pas vrai que c'est lui qui a tout récemment démis Taha Hussein de ses fonctions à l'Université du Caire?

Outre le blocage des membres de l'Institut envers l'adoption du système tempéré, on retiendra contre ces derniers leur attitude envers les novateurs de la musique égyptienne : Sayyid Darwîch, Muhammad 'Abd al-Wahhâb et Umm Kulthûm. Ces faits seront amplement rapportés. On rappellera que certains d'entre eux avaient pu dire, à la mort de Sayyid Darwîch : "Laqad mâta al-hals fil-l-balad » (C'en est fini de la débauche dans le pays) ${ }^{37}$.

Rétrospectivement, l'attitude "protectionniste» des membres de l'Institut, non clairement exprimée pendant le Congrès, le sera dans un opuscule rédigé dix ans plus tard par son vice-président technique, Muhammad Fathî Bey, reprenant dans son titre 
le propos initial du Congrès ${ }^{38}$ afin de déplorer le laxisme des autorités gouvernementales dans l'application de ses recommandations. On y voit l'anathème jeté explicitement contre les créations modernistes attribuées à «des artistes analphabètes ». D'un point de vue très moraliste, les épithètes accolées à ces formes nouvelles sont celles de muyâ'a et de takhannuth, vocabulaire, nous allons le voir, qui traverse les tendances. Avec une certaine lucidité sont pointés ici les responsables de cette acculturation: le disque et le cinéma. L'auteur stigmatise l'apparition d'un orchestre national de musique occidentale nouvellement créé par le ministère de l'Instruction publique, quand celui-ci était sensé appliquer les résolutions du Congrès visant à la renaissance de la musique arabe. On observe pourtant des contradictions flagrantes qu'il est important de relever. Dans leur aspiration à une seconde nahda, les réformateurs affrontent une musique européenne envahissante. Ils affrontent aussi un courant de jeunes musiciens travaillant à une pareille renaissance (Muhammad 'Abd alWahhâb, Umm Kulthûm) mais ouverts à la musique occidentale. Toutefois, combattant celle-ci et ceux-là, ils adoptent des positions contradictoires. Partisan d'une défense absolue de l'authenticité de la musique arabe, Muhammad Fathî Bey reproduit en fin d'ouvrage le débat du Congrès sur la double question du style et de l'adoption des instruments européens à tons fixes ${ }^{39}$. Ne contredisant pas l'opinion de Curt Sachs suivant laquelle «c'est le style de la composition qui détermine la création des instruments et non les instruments qui commandent le style ", il la contourne en axant la question sur l'expression. Pour lui, « ces instruments (orientaux) ne sont en vérité que des moyens d'exprimer un seul sentiment humain parmi tant d'autres, dans lequel, par malheur, se sont spécialisées nos compositions: le sentiment de l'amour». Le raisonnement est spécieux (il sera repris sans cesse ultérieurement, cf. infra). N'est-ce pas là revendiquer de manière déguisée, à travers l'inexpressivité supposée des instruments orientaux, le dépassement de l'expression maqâmienne appuyée sur le takht, ce qui équivaudrait en fin de compte à revendiquer un autre style, d'autres formes? N'est-ce pas viser, à travers la revendication d'une totalité des sentiments humains, l'universalité si chère aux modernistes? En outre, peut-on adopter le piano sans contrevenir au système tonal arabe? À ce propos, M. Fathî ne craint pas de dire : «Les notes musicales [...] sont universelles et comprises par tout le monde »! On le voit, la tentation de l'expressivité et de l'universalité n'est pas que le dada des modernistes, elle mène à une confusion qui apparaît avec une récurrence troublante tout au long de ce débat.

Pour revenir à notre thème initial, peut-on considérer le Congrès du Caire comme une tentative d'appropriation des « attributs symboliques » de la centralité ? Autrement dit, à travers ce Congrès, l'Égypte revendique-t-elle - officiellement - la position centrale qu'elle occupe d'ailleurs depuis quelques décennies ? Sans doute non. Plutôt faudrait-il voir ici l'expression d'une consécration (à la date du Congrès, le luth égyptien remplace déjà le 'ûd 'arbî au Maghreb, type de ûd (luth) dont Khemayyes Ternân est le dernier représentant). Si de nombreux membres non égyptiens du Congrès avaient clairement défini l'Égypte comme « le centre musical du monde arabe » (Wadî' Sabra, Ra'ûf Yakta Bey), pour les questions essentielles, l'Égypte n'a pas tenté d'imposer ses vues. Devant l'impossibilité d'une entente, 'Abd al-Wahhâb propose de ne pas tenir compte de l'avis des autres pays arabes et prône l'adoption, pour l'Égypte, du système tempéré ${ }^{40}$. De même, mais avec des raisons inverses, le violoniste Sâmî al-Chawwâ demandera et obtiendra un amendement aux points 1 et 3 du programme de la commission de 
l'échelle musicale ${ }^{41}$ visant à remplacer la notion de "gamme arabe » par l'expression "gamme égyptienne".

Les conclusions du Congrès International de Musique Arabe réuni à Bagdad du 28/11 au 5/12/1964 montrent à l'évidence que ce problème de l'échelle musicale arabe n'a pas été résolu (point 7) et que la création prévue en 1932 d'une Académie de Musique Arabe ayant à connaître de cette question est toujours attendue ${ }^{42}$. On voit ici combien le poids de la pratique musicale a primé sur les tentatives idéologiques et réformatrices. Ce débat reviendra inlassablement dans les décennies suivantes, autour de la question: "Quelle musique?»

\section{Troisième jalon pour une chronologie de la réforme musicale en Égypte}

\section{L'essence de la musique égyptienne : vers une troisième nahda?}

58 Au cours de l'année 1955, une campagne est déclenchée dans la revue al-Idhâ' $a^{43}$, organe de la radio d'État, par les journalistes «Sam », Muhammad Galâl Ahmad et Muhammad Sulayman Gamîl. Le même objectif réformateur est annoncé : "Le but de cette bataille est de dégager les traits de l'art musical en Égypte et de le protéger de l'anarchie. $»^{44} \mathrm{Le}$ mot d'ordre aurait d'ailleurs été lancé par le général Neguib lui-même, donnant, dès le lendemain de la révolution, les directives nécessaires pour «sortir la musique égyptienne de l'état d'arriération et de léthargie dont elle a souffert par le passé et expurger les airs égyptiens et arabes des accents de mièvrerie (muyû'a)et de désespoir [...] qui ont déteint sur la personnalité égyptienne et l'ont empreinte de passivité, d'indolence et de laxisme ${ }^{45}$. On voit quelle importance - et quel pouvoir! - sont reconnus à la musique par les nouveaux dirigeants et l'ampleur de la tâche imposée dorénavant aux musiciens et chanteurs. La leçon semble avoir été retenue : de 1954 à 1958 Umm Kulthûm n'enregistre pratiquement aucun texte dans le registre sentimental, limitant presque totalement sa production aux thèmes patriotiques.

Toute la question est désormais centrée autour de deux axes : identité et nationalisme. Le dénommé Sam interpelle les grands chanteurs et compositeurs, Muhammad 'Abd alWahhâb, Riyâd al-Sunbâti, Zakariyâ Ahmad, Umm Kulthûm, posant la question: "Qu'est-ce que la musique égyptienne? Ces nouvelles formes importées ou ces vieux layâlî et tawâchih turcs?» Concernant Muhammad 'Abd al-Wahhâb, il demande: "Quelle philosophie lui a suggéré d'emprunter à la musique connue en Europe et en Amérique [...] pour en faire ses chansons orientales?» puis Zakariyâ Ahmad: "Sa musique est-elle réellement orientale ou bien turque, héritée de l'impérialisme ottoman, ou procède-t-elle des tawâchih arabes dont nous avons hérité par le biais des dhikr-s et des mouleds et qui sont restés dans nos coeurs avec les autres traces de l'occupation arabe? » Enfin, abordant la nouvelle école instituée par Riyâd al-Sunbâtî et Umm Kulthûm : « Riyâd al-Sunbâtî doit dire en quoi consiste exactement, d'où vient et ce qu'exprime sa musique nouvelle à nos oreilles et à nos consciences; dans quelle mesure elle est marquée par le caractère égyptien et imprime celui-ci en retour.» Muhammad Galâl Ahmad pose quant à lui la question: "Retournons-nous sur notre vieux turâth et examinons-le : mérite-t-il de coexister avec ce à quoi nous sommes parvenus aujourd'hui, ou bien y a-t-il des nécessités nouvelles nous imposant de le transformer complètement? Tel est le problème : notre musique orientale convient- 
elle à notre nouveau niveau de conscience ou bien avons-nous besoin d'un autre type de musique en accord avec notre affectivité et nos sentiments présents?»

Dans les réponses, plusieurs tendances se font jour :

1. «traditionalistes» de l'Institut de Musique Arabe, partisans du qadim mais non sans ambiguïté ;

2. «fusionnistes » modérés, partisans d'un métissage harmonieux ;

3. «acculturationnistes », partisans inconditionnels de la musique occidentale et désireux de se débarrasser définitivement du quart de ton;

4. «mondialistes», partisans d'une musique alignée sur les normes «universelles» (apparentés aux précédents mais moins idéologues);

5. « séparatistes » qui veulent garder le quart de ton pour la musique populaire et adopter le « demi-ton» pour une nouvelle musique nationale.

61 Pour Muhammad Fathî, doyen de l'Institut de Musique Orientale, et Ibrahîm Chafîq, professeur, pas question d'emprunts à la musique occidentale (sauf, on l'a vu, ses instruments). Ils proposent la formation d'un comité artistique interdisant que soit diffusée à la radio toute musique ne répondant pas à certains critères d'authenticité. Ici, et c'est bien là la marque de la confusion qui domine cette campagne, le conservatisme est crédité des attributs du nationalisme et de la lutte anti-coloniale (Pachas et fellahs même combat !). L'auteur écrit :

« Notre musique doit trouver sa source dans les sentiments du fellâh égyptien et dans sa lutte pour la subsistance [...]. Ces vérités, un groupe de compatriotes sincères en a eu conscience ${ }^{46}$ en 1913 et s'est réuni au domicile d'un compatriote non moins dévoué, maître Mustapha Rida Bey, pour arrêter les menées perfides (sic)et l'oppression des colonialistes [...], puis les hypocrites ont fourni au roi Fouad une nouvelle occasion de fourrer son nez dans cette entreprise glorieuse (la création avec leurs fonds personnels du Club de Musique Arabe) et de se l'attribuer en son nom propre comme à son habitude. »

Il apparaît qu'en ce début des années cinquante, l'Institut, délaissé par l'État, est au bord de la faillite. Les « fusionnistes » revendiquent le nationalisme en recherchant une voie moyenne entre la musique « classique » orientale et la musique occidentale. Yahyâ al-Laythî, professeur d'harmonie à l'Institut des professeurs de musique (femmes) résume la synthèse qui doit se faire :

«On aurait tort de rejeter la musique orientale, sa beauté, son tarab, la délicatesse de ses modes et de ses rythmes dans le but d'être à $100 \%$ Occidentaux dans notre musique, de même qu'on aurait tort de rejeter la musique occidentale qui est universelle en raison de sa perfection et de sa puissance pour être à $100 \%$ Orientaux dans notre musique [...]. Une musique purement égyptienne existe. Certes, elle n'obéit pas à un langage artistique défini comme la musique occidentale mais nous avons grand espoir d'éliminer ce défaut. »

63 Une position extrême appelle au dépassement de la notion de nationalisme vers des formes d'expressions "universelles» ('àlamiyya).Décrivant la création de l'Orchestre Symphonique National, Muhammad Sulayman Gamîl préconise l'adoption sans conditions de la musique occidentale et la mise en avant de l'opéra et de la symphonie, applaudissant la création prochaine d'un premier opéra égyptien composé par le Dr. Muhammad Mahmûd Sâmî, diplômé du Conservatoire de Paris. Dans une rhétorique toute révolutionnaire, il développe la métaphore de l'usine : «On sait bien que la petite usine ne parvient pas à satisfaire les besoins croissants de la population. De la même façon, le takht égyptien ne parvient pas à exprimer l'âme des révolutionnaires et à 
pousser le peuple dans la bataille de la liberté et de la vie. Or, nous avons autant besoin désormais d'orchestres symphoniques que de grandes usines! " La musique populaire est pour lui «une collection de chants à l'état brut qui vivent avec les gens à la campagne ou au désert et constituent la matière qu'il faut polir, dont il faut préparer les outils et les moyens de création nécessaires à sa mise en valeur et à son développement [...] afin de l'organiser scientifiquement et de la présenter dans les nouveaux habits de la grande composition musicale. » 'Abd al-Hamîd Tawfîq (fondateur de la firqat al-'anghâm al-mûsîiiyya) affirme :

« Notre musique pourra devenir une musique à portée humaine universelle quand elle se sera débarrassée du quart de ton qui constitue un grand obstacle au développement et au progrès de la musique orientale ${ }^{47}$. Je ne sais pas pourquoi l'on voudrait que nous nous enchaînions à la musique des siècles passés : est-ce que nous étudions aujourd'hui la chimie de Jâbir Ibn Hayyân et la médecine d'Ibn Sînâ pour qu'on nous impose la musique d'al-Farâbî ou d'Abû Sîrî ? [...] Il faut développer la musique populaire, l'affiner et composer des pièces authentiques tirant leur trame musicale de ces chansons. Nous sommes las de la mollesse que véhiculent ces instruments déficients que sont le 'ûd, le qânûn et le nây» (nay: flûte droite en roseau).

Kamâl al-Nagmî, rétrospectivement ${ }^{48}$, mentionne l'échec de cette tendance auprès des auditeurs arabes, prenant le double exemple de la chanson Wanâ koll-e-mâ gûl at-tûba yâa bûy, chantée par 'Abd al-Halîm Hâfez, et, dans un autre registre, de la création par Abu Bakr Khayrat, à partir d'une phrase musicale de Sayyid Darwîch, d'une oeuvre orchestrale grandiloquente, expérience restée célèbre sous le nom de la séquence du texte d'origine êh-l-Ibâra.

Pour Husayn Gunayd (chef de la firqat Umm Kulthûm li-l-mûsîqâ al-'arabiyya),la musique égyptienne existe,

« elle est née avec Sayyid Darwîch et essaye vaillamment de prouver son existence. Les difficultés qu'elle rencontre proviennent du système suivi dans le dernier quart de ce siècle, à savoir l'enseignement des bases de la musique turque et de ses règles aux débutants qui se sont imprégnés de l'esprit turc et se sont infiltrés parmi les compositeurs qui se basaient sur leur effort de création personnelle. C'est pourquoi la plupart des compositeurs qui sont apparus dans le dernier quart de ce siècle n'ont pas étudié suffisamment leur art et je propose l'envoi de missions de compositeurs suffisamment préparés pour étudier les bases de la musique universelle. »

Enfin, Muhammad Bakhît, secrétaire du Syndicat des musiciens, distingue entre musique locale et musique mondiale : "Le problème de la musique en Égypte réside dans le "quart de ton". Nous ne demandons pas qu'il soit abandonné mais seulement conservé dans notre musique populaire. Toute musique qui s'affranchit de l'harmonie est une musique morte ! [...] Il faut laisser le quart de ton à notre musique locale et utiliser le ton et le demi-ton sur la base du système universel unifié et produire sur cette base sans craindre pour notre caractère national. »

Quant aux compositeurs eux-mêmes, leur position est unanime à reconnaître l'existence d'une musique égyptienne authentique qui exprime l'affectivité des Égyptiens.

68 'Abd al-Wahhâb affirme :

« Les traits de notre musique sont éminents. Ils ont commencé à saillir avec 'Abduh al-Hamûlî, Cheikh Salâma Higâzî et Sayyid Darwîch. Nous, aujourd'hui, essayons de commencer là où ils se sont arrêtés et notre travail se résume à faire évoluer la musique et la mettre sur la voie du progrès qui gouverne le pays. Je tiens à dire ici 
que progrès ne signifie pas emprunt mais plutôt une certaine perception qu'a l'artiste des idées, des arts et de la vie universelle qu'il essaye d'assimiler et de refléter dans sa production [...]. S'il advenait qu'un poète européen invente un nouveau mètre en poésie et qu'un poète (égyptien) s'en empare et écrive un poème sur ce schéma en puisant au milieu égyptien authentique, ce qu'a fait le poète égyptien devrait être considéré comme un nouveau développement de la poésie égyptienne, non comme un emprunt à autrui. [...] Mais la première difficulté est que le peuple n'est pas préparé à ce progrès. »

Farîd al-Atrache déclare :

«La plupart des morceaux que nous entendons aujourd'hui sont de la musique égyptienne authentique qui émane de notre sensibilité et que nous importe de savoir si elle est d'essence turque ou étrangère! [...] Nous n'avons fait jusqu'à maintenant que la développer afin de l'adapter à notre époque. Ainsi, nous l'avons affinée et condensée en minutes quand elle durait des heures, ceci par l'utilisation de rythmes nouveaux, différents des anciens inconnus du grand public, et de divers instruments, orientaux et occidentaux confondus, tout en préservant la couleur orientale ancrée au fond de nous. "

70 Farîd al-Atrache propose en outre « la création d'une commission artistique qui aurait pour mission de revoir les mélodies et les chansons avant leur diffusion afin d'écarter les intrus de l'art musical ».

Pour Muhammad al-Mûgî enfin : «Il est certain que le vol des mélodies occidentales qui se répand parfois dans notre musique doit être combattu en tant que délit de droit commun $» !^{49}$

72 Cette campagne se termine par la parole donnée au peuple. À travers les témoignages d'un groupe d'hommes et de femmes, employés, fonctionnaires, étudiants, reviennent les mêmes thèmes : pas de musique répondant aux nouvelles aspirations du peuple; la place de Sayyid Darwîch reste vacante; l'Égypte attend un artiste, un artiste qui exprime les sentiments des millions de travailleurs, la lutte silencieuse du fellah pour la subsistance. Un artiste qui aille vers l'ouvrier dans son usine et l'aide à lever la main pour poser une nouvelle pierre dans l'édification de sa patrie. Les attributs accordés à Sayyid Darwîch sont ceux de quwwa (force, tonus) et de rujûla (virilité) et ceux attribués aux artistes actuels : takhannuth (caractère efféminé) et muyû'a (mièvrerie). Les artistes ne font qu'emprunter à l'Occident sous couvert de progrès. De grands musiciens actuels doivent être considérés comme étrangers à l'Égypte, aux souffrances de l'Égypte et aux rêves de l'Égypte. On redemande (encore !) la création d'instituts et l'organisation de Congrès pour résoudre le problème de la faiblesse de la musique égyptienne et étudier les bases de la musique arabe. Il faut en finir avec l'analphabétisme des musiciens et les soumettre à des examens (proposition déjà avancée au Congrès de 1932).

On voit que, finalement, les sentiments dominants en 1955 ne sont pas très éloignés de ceux de la révolution de 1919 et que l'exigence nationaliste aboutit dans un cas comme dans l'autre à une nouvelle exigence esthétique dans le domaine musical, esthétique basée sur l'expressivité, elle-même dictée par le besoin d'extériorisation du «souffle révolutionnaire ». Malgré l'amalgame entre tradition savante de la nahda et musique ottomane et, par conséquent, la fermeture du débat sur la seule alternative " musique turque ou musique occidentale?", évacuant par là toute référence à l'apport de la musique religieuse dans l'édification d'une renaissance endogène soucieuse déjà d'une spécificité nationale (la tendance doucement laïque du nouveau régime veut-elle ainsi évacuer sans le nommer le référent religieux ?), une certaine continuité historique du sentiment nationaliste s'affirme. 1952 n'a pas jeté 1919 dans l'oubli. Il n'est pas 
étonnant dans de telles conditions que la seule figure qui ressorte entièrement blanchie de cette accusation de métissage soit celle de Sayyid Darwîch, mukhadram par excellence, absous tout à la fois de sa formation à l'école ancienne et de ses emprunts à la musique occidentale. Le musical devient aléatoire. Désormais, le seul critère retenu de l'authenticité musicale égyptienne est celui du nationalisme et de l'attention portée au peuple. D'où, en toute logique, un intérêt particulier et nouveau envers le folklore. Seule alternative entre héritage turc et musique occidentalisée, il devient la marque de l'authenticité nationale.

«Notre opération de promotion du folklore, déclare Tâhir Abû Zayd, auteur d'émissions de radio sur le folklore ${ }^{50}$, n'est pas un caprice ou une mode mais un travail essentiel visant à la connaissance de notre peuple, nous permettant de l'étudier, de le comprendre, de le faire évoluer, participant en cela au renforcement $\mathrm{du}$ nationalisme égyptien que des années de colonialisme ont battu en brèche. On sait que le chant égyptien (ghinâ)est en crise et que nos airs sont pauvres et décadents (râkida), consistant soit en de vieux rythmes orientaux visant à créer le tarab et réjouir l'oreille ou bien en des mélodies occidentales affreuses qui ne nous émeuvent pas et ne font pas vibrer nos sentiments. Nos airs populaires - et eux seuls - sont la source véritable qui exprime notre être [...]. Le grand Sayyid Darwîch n'est devenu grand que parce qu'il s'est appuyé sur les airs populaires - sur le folklore - qu'il a introduit dans notre musique et a mis en forme pour exprimer à travers lui la vie des travailleurs, des paysans, le soleil du matin, la gargoulette en terre, la pauvreté et l'occupation étrangère. En collectant le folklore, comme l'ont fait les grandes nations de ce monde, on obtient un art qui n'est pas dépourvu de racines mais qui au contraire «colle » aux gens et s'avère l'arme la plus pénétrante pour assurer l'unité, appuyer le nationalisme. La plus puissante expression de notre dernier affrontement avec le colonialisme (agression tripartite, n.d.t), je ne l'ai pas vue au cinéma ou au théâtre, je ne l'ai pas entendue à une émission de radio, je l'ai vue dans l'art populaire, entendue de la bouche du 'arâgeuz (théâtre d'ombres). » de collecter le folklore des différentes régions en vue de la création d'une troupe folklorique nationale. L'année 1957 voit la création du Markaz dirâsât al-funûn alcha'biyya. Le folklore, «la chanson populaire » sont posés comme catégories en vertu d'une idéologie qui tente d'opposer al-ghinấ' al-cha'bî lal-ghinâ' al-mutqan, (chant populaire/chant savant), faisant éclater l'histoire des genres qui souvent ne dissocie pas. La taqtûqa refuse par excellence cette dichotomie. Le mawwâl, forme populaire, a toujours fait partie intégrante du répertoire classique. Les deux termes ne sont pas davantage isolés dans l'oeuvre des compositeurs ou dans le répertoire des grands chanteurs. Comme le dit Kamâl al-Nagmî $\hat{\imath}^{51}$ : « Munira al-Mahdiyya a chanté un nombre considérable de chansons populaires. Or, en son temps, il ne serait venu à l'idée de personne de la qualifier de 'chanteuse populaire' ou 'folklorique' !»

Pour conclure, on voit que tout au long de son élaboration, le discours musical né en Égypte, par delà son rayonnement, est traversé de multiples soubresauts engendrés par la confrontation technique, économique et culturelle avec l'Occident. Le débat théorique-idéologique qui l'entoure et parfois le sous-tend révèle la constante recherche d'une identité. Musiciens cobayes (1932) ou compositeurs consacrés, il a aussi pour particularité de n'être jamais celui des intéressés. Dans les années cinquante, la musique égyptienne est définitivement engagée dans un processus d'universalisation nullement dialectisé par ses promoteurs. On considère d'ailleurs, insistant sur ce fait, que le pas fatidique marqué par l'utilisation de l'harmonie n'a pas été franchi par Muhammad Abd al-Wahhâb, lequel s'est toujours limité à la notion occidentale 
d'orchestration (tawzî).L'emprunt à l'Occident n'a donc pas affecté l'essence strictement monodique de la musique arabe, ceci malgré des tentatives d'harmonisation élémentaires et partielles (arpèges, accords plaqués de cordes) et même si l'effet produit par l'augmentation de la masse orchestrale (trois octaves dans le takht contre cinq environ dans l'orchestre symphonique) a pu donner parfois cette illusion. Aussi bien, pour les grands compositeurs, l'histoire de la musique égyptienne peut s'énoncer sur un mode linéaire et cumulatif où les éléments stylistiques et orchestraux empruntés ne sauraient être considérés comme ayant occulté le vieux fonds arabe. Il n'y a pas pour eux de contradiction et ce débat ne les concerne pas. D'où le titre de l'article liminaire de la campagne décrite plus haut "Al-mûsîqâ : ma'raka lâ yadkhuluhâ ashâbuhâ ». Comment pouvait-il en être autrement ?

Cet énoncé linéaire de l'histoire musicale de l'Égypte moderne s'exprime aussi concernant les genres. Pour Muhammad 'Abd al-Wahhâb, pas de coupure significative entre 'Abduh al-Hamûlî et son propre travail de compositeur. Posant à Naguib Mahfouz, fin mélomane, et dont la Trilogie comporte de multiples références à la chanson égyptienne, la question de savoir pourquoi la grande tradition inaugurée par 'Abduh et al-Manyalâwî s'était interrompue, il m'avait répondu, l'air ébahi : "Comment ça, interrompue, mais elle vit, dans 'Abd al-Wahhâb, dans Umm Kulthûm!» Pourtant, objectivement, force est de constater que chaque genre, chaque forme qui s'élabore jette définitivement celle qui l'a précédée dans l'oubli. Comme en Occident, faut-il que ce qui a précédé soit maudit? Nous avons vu qu'ici d'autres facteurs sont à l'œuvre. Quoi qu'il en soit, qui peut aujourd'hui au Caire écouter un représentant de bon aloi de l'école ancienne ou même des chansons extraites du théâtre lyrique si ce n'est sous la forme fossile et académique défendue par la firqat al-mûsîâ al-'arabiyya? La mémoire artistique égyptienne n'entretient pas - du moins économiquement - ses symboles. Aucun système de production ne défend des genres ou des œuvres délaissées par le plus grand nombre. Telle serait à notre avis l'un des traits, certes fâcheux, mais des plus remarquables de la spécificité égyptienne. Est-ce là le prix à payer de la centralité ?

\section{L'Égypte, centre musical du monde arabe ?}

Si c'est véritablement l'essor des grands media à partir des années trente (cinéma parlant en 1932, création de la radio d'État en 1934) et plus encore après la seconde guerre mondiale, qui a déterminé la position centrale de l'Égypte dans le domaine de la chanson, il convient de préciser que cette influence est plus ancienne. L'émigration des artistes vers l'Égypte date du XIXe siècle quand nombre de Syro-Libanais fuient la tutelle ottomane ou l'esprit rétrograde des élites religieuses citadines ${ }^{52}$. À la même époque, troupes de théâtre égyptiennes, chanteurs et chanteuses égyptiens sillonnent le monde arabe, de l'Irak au Maghreb. Les journaux et revues mentionnent en bonne place ces tournées qui, avant la commercialisation du disque à grande échelle, sont pour les artistes égyptiens le seul moyen d'élargir leur renommée. Si avant le siècle l'Égypte est sur les marges (ce sont les troupes de théâtre syro-libanaises qui viennent en Égypte, celles notamment de Yûsuf al-Khayyât, d'Abû Khalîl al-Qabbânî), dès les années 1910 les nouvelles formes de théâtre chanté élaborées en Égypte déplacent définitivement le centre de gravité. Salâma Higâzî (1853-1927) présente ses opérettes en Syrie, Liban et Tunisie. Dans le domaine du théâtre et de la chanson tout se passe désormais au Caire. L'essor de l'industrie du disque va amplifier le phénomène. Les 
artistes syro-libanais viennent en nombre au Caire, cette fois-ci pour enregistrer et se faire connaître (Farjallah Bayda, Muhammad al-'Achiq). Certains vont jusqu'à adopter la prononciation égyptienne du " gîm ", comme Muhyi al-Dîn Ba'yûn, dans des qasîdasde forme égyptienne, avec rythme et orchestration. Le phénomène revêt une telle ampleur que la compagnie libanaise Baïdaphon déplace rapidement le gros de ses activités au Caire. Le phénomène ne concerne pas que le Machreq. Frédéric Lagrange souligne $^{53}$ que "les catalogues maghrébins de compagnies comme Gramophone ou Baïdaphon, installées très tôt à Tunis et à Alger, se font l'écho d'une égyptianisation marquée du répertoire dès le début des années 20 , rarement par une reprise des chefsd'oeuvre de l'art khédivial mais le plus souvent par des adaptations locales des taqâtîq légères ou grivoises les plus en vogue au Caire (répertoire des chanteuses juives en Tunisie).»

En Algérie, le souffle rénovateur de la nahda a tourné les yeux de l'intelligentsia vers le Moyen-Orient (visite historique de Muhammad 'Abduh en 1903). Durant les années vingt, des troupes égyptiennes sont invitées à se produire à Alger, parmi lesquelles celle de Georges Abyad, plus tard de Fâtima Ruchdî. « Les artistes algériens, écrit Nadya Bouzar-Kasabgi ${ }^{54}$, animés par un brûlant désir de "modernité ", sont confortés dans leurs expériences novatrices en découvrant les arts du spectacle égyptien. »

En Iraq, où le chanteur Muhammad 'Abd al-Wahhâb, le Chanteur des Rois (Mutrib almulûk),était un habitué de la cour du roi Faysal, l'influence égyptienne était présente. Dès 1926, Muhammad al-Qubbândjî avait abandonné la formation attitrée du maqâm (almaqâm al-'irâqî) pour un ensemble de type oriental incluant le 'ûd et le qânûn. Le Cheikh Djalâl al-Hanafî déclare s'être battu à cette époque pour dissuader al-Qubbândjî d'imiter les chanteurs égyptiens $s^{55}$. Cette tendance sera perceptible encore chez lui lorsque, au Congrès du Caire, il déclare avoir tenté d'émouvoir le public égyptien en raison de l'écho que la musique égyptienne avait dans le coeur des Iraqiens.

On pourrait multiplier les exemples. Ceux-ci suffiront à montrer que l'influence de l'Égypte est déjà certaine et étendue à l'ensemble du monde arabe dès avant l'essor des deux grands media qui vont asseoir définitivement son hégémonie: le cinéma et la radio. Les débuts du cinéma et la création des studios Misr en 1936 font affluer les artistes arabes vers le Caire: Jeannette Feghali devient Sabah, Alexandra Badran devient Nûr al-Huda. Les règles du jeu sont simples, écrit Frédéric Lagrange ${ }^{56}$ : "Abandonner tout particularisme confessionnel quitte à changer de nom, dialectal pour adopter le parler du Caire et musical en épousant le modèle de l'école musicale égyptienne.»

81 La liste des chanteurs et chanteuses arabes totalement égyptianisés, pour beaucoup installés en Égypte, serait trop longue. Citons pour mémoire la libanaise Fayza Ahmad, le syrien Fahd Bellân et plus récemment son compatriote Arkân Fu'âd qui se sont fondus totalement au moule égyptien. Le phénomène sera amplifié par la guerre du Liban qui a incité de nombreux chanteurs libanais à s'établir en Égypte (Walîd Tawfîq, Najâh Sallâm). Des «tandems » à succès se sont créés entre compositeurs égyptiens et chanteuses arabes étrangères(Fayza Ahmad-Muhammad Sultan ; Warda-Balîgh Hamdî). Dans un premier temps donc, et traditionnellement, c'est le Moyen-Orient qui fournit les plus forts contingents d'artistes à l'Égypte. Aux alentours de 1975, après la mort d'Umm Kulthûm, le mouvement migratoire change d'origine après, dit-on, le refus de Fayrûz de s'installer au Caire. C'est le Maghreb qui vient à la relève du Levant. Warda en est le premier et le plus illustre exemple. Elle chante des thèmes nationalistes à la 
gloire de sa patrie d'adoption et reprend le créneau de la chanson longue occupé uniquement avant elle par Umm Kulthûm et largement délaissé aujourd'hui par les chanteuses égyptiennes.

Cette « égyptianisation forcée » des chanteurs arabes est un phénomène constant qui ne s'est interrompu qu'à une date toute récente. Farîd al-Atrache, dont l'accent levantin est au début apprécié des Égyptiens, se débarrasse vite de ce "défaut». Sa soeur Asmahân, dans le film Gharâm wa-ntiqâm 1945) fait semblant - en bonne Égyptienne ! - de ne pas comprendre le dialecte libanais. Ce forçage se fait notamment par une reprise du folklore. Dans les années trente, l'un des numéros favoris de la danseuse libanaise Badî'a Masâbnî, tenant cabaret au Caire, est celui où elle apparaît vêtue de la melayet leff (long voile noir enveloppant tout le corps) portant le ballâs (grosse poterie ronde à anses) sur l'épaule. Farîd al-Atrache égyptianise son répertoire en reprenant des thèmes populaires tels Aki al-balah helu bass en-nakhl fe-l'âlî (mawwâl traditionnel), 'Anâ kont-e-sayyâd samak we sîd as-samak gheyya(mawwâl sa 'îlî deMuhammad al-'Arabî) ou Lêh techtekî ardenâ wa-n-nil sâqîhâ, chanté en duo avec sa sœur Asmahân. Volonté d'égyptianisation ou obéissance à la nouvelle idéologie « folkloriste » qui s'installe?

Tous les moyens dont a profité l'Égypte pour asseoir son hégémonie culturelle ont pu conduire au cours d'une certaine période à des attitudes typiques de peuples en situation d'impérialisme. Muhammad al-Qubbândjî raconte qu'ayant lu devant son ami Ahmad Chawqî une qasîda de Muhammad Sa'îd al-Habbûbî et que Chawqî, intéressé, lui demandant qui était ce poète, il s'exclama : « Comment, le dernier des Irakiens connaît le nom d'Ahmad Chawqî et Ahmad Chawqî lui-même ne connaît pas celui du plus grand poète irakien? $\aleph^{57}$. J'ai connu personnellement nombre de musiciens maghrébins fiers de posséder, contrairement aux Égyptiens, un double langage musical et un double répertoire: leur répertoire traditionnel local (modes et rythmes) et le répertoire égyptien. Il faut le reconnaitre, cette fierté se doublait souvent dans leur bouche d'une stigmatisation du chauvinisme égyptien marqué par un manque de curiosité, pour ne pas dire dédain, vis-à-vis des autres formes musicales du monde arabe. Il faudrait aujourd'hui démentir ce mythe. L'Égypte, si elle a créé un modèle culturel dans le monde arabe, a aussi beaucoup reçu de lui et est restée très à l'écoute des productions périphériques. Ce fait, sous l'émergence de données économiques nouvelles, va en se généralisant. Des chanteuses comme les tunisiennes Latîfa, 'Ulayya at-Tunsiyya ou la marocaine Samîra Sa'îd accédaient certes à la célébrité en émouvant le public égyptien par la reprise d'une des grandes chansons d'Umm Kulthûm mais étaient aussi appréciées dans leur dialecte. Dans les années 50 et 60 , une soirée mensuelle nommée Haflat adwâ' al-madina invitait des chanteurs de tout le monde arabe à se produire au Caire, chacun chantant dans son dialecte. Si jusqu'à une période récente, il suffisait que l'un des grands compositeurs égyptiens d'aujourd'hui, tels Muhammad al-Mûgî, Kamâl at-Tawîl, Balîgh Hamdî, Sayyid Makkâwî ou Hilmî Bakr compose pour de jeunes chanteurs d'autres pays arabes pour assurer leur célébrité, il semble que la règle ne soit plus de mise aujourd'hui. Nombre d'entre eux peuvent se tailler un honnête succès en Égypte en chantant dans leur dialecte, que celui-ci soit ou non compris des Égyptiens. Parallèlement, le phénomène d'édification du dialecte égyptien comme "intégrateur " des autres dialectes a vécu. 'Abd al-Halîm Hâfez avait l'habitude, lors de ses tournées en pays arabes, de chanter dans le dialecte d'origine une chanson locale qui était enregistrée et rediffusée en Égypte, où les Égyptiens pouvaient l'apprécier. Cependant, dans des chansons comme Yà halî yâ halî (rythme Sôt des pays du Golfe) ou Yurid Allah 
yurîd Allah, le dialecte n'est pas entièrement celui du Golfe. Ce dernier n'est ici que citation, ou prétexte. C'est le dialecte égyptien, plus exactement cairote, qui enserre un dialecte périphérique. Il faudrait en effet se demander si ce phénomène n'a pas joué en Égypte même, le dialecte cairote absorbant les dialectes campagnards. Aujourd'hui, le phénomène est inversé, ou moins systématique: ce sont les dialectes arabes périphériques, pas toujours entièrement compris des Égyptiens, qui connaissent un honnête succès en Égypte.

On distingue trois zones :

1. Soudan : La chanson soudanaise est très prisée en Égypte. Un chanteur comme 'Abd al-Karîm al-Kâbli est très aimé du public égyptien. Le catalogue de la compagnie nationale Sono-Cairo met en vedette sur au moins cinq pages les chanteuses et chanteurs soudanais enregistrés et distribués au Caire.

2. Libye : Il y a aujourd'hui un véritable "phénomène libyen » en Égypte, cristallisé en la personne de Hamîd al-Châ'irî. Ce chanteur s'exprime en pur dialecte libyen. Ses chansons sont rythmées de claquements de main à la façon bédouine sur des rythmes lîbî. Il a déclenché une véritable vague en Égypte et compose maintenant pour de jeunes chanteurs égyptiens comme 'Alâ' 'Abd al-Khâliq, Simûn ou Anuchka.

3. Pays du Golfe: C'est un phénomène économique relativement nouveau et, sujet sensible, difficile à étudier. Des hommes d'affaires du Golfe investissent massivement dans la production musicale égyptienne (en particulier l'industrie de la cassette qui représente en Égypte un marché d'une capacité de quinze millions d'unités par an) en s'associant, comme la loi l'exige, avec des partenaires égyptiens. Il misent sur des noms égyptiens «qui marchent " du type 'Ali al-Haggâr et en profitent pour «faire passer » leurs vedettes nationales. Des chanteurs comme Muhammad 'Abduh, Talal al-Maddâh, la chanteuse 'Itâb, établie au Caire, tous trois Saoudiens, font des tournées et ont du succès en Égypte, chantant dans leur dialecte et sur leurs rythmes mais se coulant aussi au moule du dialecte égyptien. 'Abd Allah al-Ruwaychid, chanteur koweïtien, a fait pleurer les chaumières avec une chanson sur la guerre du Golfe : Allahumma lâ-'tirâd ${ }^{58}$. Toutefois, si l'on veut qu'une soirée organisée pour un chanteur koweïtien ou autre marche au Caire, il faut que chantent avec lui dans la même soirée des noms égyptiens connus, sauf cas exceptionnels comme Fairûz qui, dit-on, n'aime pas venir au Caire à cause de la foule.

N'oublions pas l'Irak dont les Égyptiens aiment le dialecte et les rythmes. Nâzîm alGhazâlî, révélé au monde arabe par une émission de la radio koweïtienne, est très aimé des Égyptiens ainsi que Sa'dûn Jâber qui, avant les derniers événements, donnait de nombreux concerts au Caire. Enfin, il semblerait que se dessine aujourd'hui au Caire l'émergence d'une variété de qualité empruntant des éléments aux folklores arabes périphériques. Une expérience digne d'intérêt est actuellement menée par un musicien de formation classique (fourvoyé il fut un temps dans une variété de mauvais goût), le qânûniste Sayyid Ragab, qui compose avec et pour des musiciens invités, originaires du Golfe et du Yémen. Est-ce l'ère d'une nouvelle fusion qui s'amorce?

Le trait dominant en Égypte aujourd'hui serait celui d'un certain cosmopolitisme illustré par l'afflux des chanteurs arabes étrangers et la multiplication des dialectes et des cultures arabes régionales. Va-t-on vers un éclectisme à outrance? Dans son dernier récital au Caire (octobre 1991), Warda n'a-t-elle pas réussi l'exploit de présenter la moitié de son tour de chant... en français?

Devenu obsolète à l'orée des années quatre-vingt, le modèle égyptien a façonné les goûts d'un large public à travers le monde arabe. Il ne faudrait pas toutefois exagérer les effets de ce débordement. Celui-ci, trop voyant, trop massif, a généré des positions 
parfois alarmistes. Nous dirions plutôt que, poussés par un idéal de modernité, nombre de jeunes chanteurs arabes ont été tentés par le modèle de la variété égyptienne. Ce qu'il faudrait mesurer, pays par pays, c'est le taux d'absorption des patrimoines locaux, ruraux ou citadins, par cette musique standardisée. Fort heureusement, des traditions régionales ont survécu dans le monde arabe et la distinction habituellement établie entre villes et campagnes s'avère inapte à rendre compte des multiples configurations. Là, des traditions citadines ont certes été affectées : au Maghreb, la musique andalouse a subi l'inflation instrumentale des orchestres égyptiens, seules de petites formations comme celle d'Ustâdh Massano ayant préservé une interprétation authentique. À Baghdad, le tchalghi al-baghdâdî perpétue une musique traditionnelle avec un ensemble traditionnel. Si a priori les attitudes de rejet sembleraient pouvoir être localisées dans des couches socio-culturelles particulières - les élites intellectuelles! - ce mode de discrimination n'est pas, là non plus, toujours pertinent. La réalité est évidemment plus complexe ainsi que le montrent les deux témoignages rapportés en annexe, traduisant des sentiments en apparence contradictoires, mais en tout état de cause jamais tranchés.

Pour ne pas conclure sur cette note triste d'une suprématie déchue, nous terminerons par une nukta (histoire drôle) qui circule encore dans les milieux musicaux maghrébins :

Trois musiciens arabes se rencontrent, un joueur de nây marocain, un joueur de kamân (ici : violon européen) syrien et un joueur de 'ûd égyptien. Le premier, pour se vanter, affirme :

- L'autre jour à Paris, salle Pleyel, j'ai fait un taqsîm d'une demi-heure qui a mis la foule en délire pendant vingt minutes.

Le Syrien, enchérissant :

- Et moi, il y a une semaine, à l'Albert Hall, j'en ai fait un tellement sublime que le dieu de la musique est descendu sur la scène pour me dire: "Tu es le plus grand joueur de kamân au monde!» Et l'Égyptien, suspicieux :

$$
\text { - Ah bon, j'ai dit ça? }
$$

\section{ANNEXES}

\section{Mostefa Lacheraf, écrivain algérien :}

« Déjà, vers les années 1936-1938, dans les restaurants populaires de la rue Randon et de la rue Marengo que nous fréquentions, certains jeunes Algériens dits "évolués" ne toléraient plus la musique andalouse ou nationale, ironisant même sur son compte, la dénigrant, et réclamant des disques égyptiens. Des cafés modernes exclusivement algériens, proches de Bab Azoun, sacrifiaient à longueur de journée au seul culte de la nouvelle musique égyptienne dans une ambiance trouble et la fumée des narguilés, et l'on savait que les indicateurs du colonel Shoen, chef tout-puissant de la police politique et parfois lui-même, étaient présents dans la salle, pour mesurer, sans doute, 
le degré de léthargie et de torpeur satisfaite dans lesquelles étaient plongés les clients, pour la plupart des intellectuels, des employés de bureau et des hommes d'affaires. Quelques-uns parmi nous, encore partagés entre l'amour de l'andalou ancien et les chansons sirupeuses et plaintives de Muhammad 'Abd al-Wahhâb, se rappelaient de la mesure autoritaire qu'avait prise, quelque temps auparavant, Kamal Atatùrk pour interdire dans son pays la musique orientale qu'il jugeait démobilisatrice et invitant au rêve et à l'oubli des réalités de la vie. $»^{59}$

\section{Mimoun Nouri, Marocain, professeur de langue et littérature arabes à Paris VIII60 :}

« Dans notre appréciation de la musique égyptienne, l'aspect politique a joué un grand rôle. Il y a eu Nasser. Nasser nous a montré que nous étions arabes. Il nous a ouvert les yeux sur les intentions de l'Occident. Il était toujours lié aux mouvements de libération. Il a installé une distinction nette entre régimes inféodés et régimes dits arabes (patriotiques, nationalistes, etc.). Il n'a jamais fait de différence dans ses discours entre l'Égypte et le reste du monde arabe. Le monde arabe fait partie de l'Égypte. Ce que disait Nasser était reflété dans les chansons d'Umm Kulthûm (Misr 'allâtî fi khâtirî wa fí damî). Ce type de chanson légère, moderniste, n'a été accepté que parce qu'il véhiculait un thème nationaliste, thème auquel nous prêtions une grande attention, par exemple : Al-'udwân al-thulâthî ('Abdal-Wahhâb) ou Qanât suwîs (Abd al-Wahhâb et Umm Kulthûm). Et puis il y a le dialecte égyptien, qui représentait pour nous le dépaysement, une sorte d'idéal d'appartenance. En le parlant, on appartient à l'Égypte, à l'arabité. C'est un dialecte qui a accédé au statut de langue classique. L'idéal à atteindre était la musique égyptienne. Et puis, rappelons-le, les grands noms de la chanson égyptienne sont liés à de grands poètes : Ahmad Chawqî, 'Alî Mahmûd Taha, Ahmad Fathî, Ibrahim al-Nâgî. Dans l'ensemble du domaine maghrébin, nul ne rivalisait avec ces gens-là. Tout cela était considéré comme de la modernité arabe non importée. En face de cela, au Maroc, un enseignement traditionnel véhiculé par des 'ulamâ' de la Qarawiyyîn qui rabâchaient.

En 1960, nous avons connu la première vague de professeurs égyptiens qui enseignaient l'arabe à partir de textes modernes, ceux de Taha Hussein, d'Ahmad Amîn. Le Kitâb al-'ayyâm, le Hadith al-arbi'â, le Hayâtî d'Ahmad Amîn nous ont fascinés. 'Umar alMukhtâr aussi. Le Rithâ' al-andalus ou le Dimachq de Chawqî sont inoubliables.

L'image de Chawqî collait à la musique sublime de 'Abd al-Wahhâb. 'Abd al-Wahhâb cultive des modes qui caractérisent la nostalgie de l'homme arabe : sabâ, hijâz, huzâm. Ici, le temps est relativement lent, au contraire de la musique populaire, rapide et bruyante. 'Abd al-Wahhâb impose le silence. Aucune différence entre un verset dit par 'Abd al-Bâset et une chanson de 'Abd al-Wahhâb. Je sors d'une profondeur pour entrer dans une autre.

Ce qu'il y avait d'extraordinaire chez Umm Kulthûm, c'est qu'elle chantait de la poésie pure avec une voix de femme. De plus, ses chansons, au début courtes et lentes, étaient écrites par des gens qui avaient une autorité intellectuelle et morale sur nous. Ensuite, c'est la chanson longue qui s'est installée : celle composée par Sunbâtî qui est particulièrement aimé pour son authenticité arabe, qui repose sur l'instrumentation: chez lui, on entend le qânûn, le 'ûd et le nây. Ce qui m'a impressionné en arrivant en 
France, c'est la courte durée des chansons. Le temps est nul dans la chanson française ! $\mathrm{Au}$ contraire, la chanson arabe cultive la répétition qui colle à la syntaxe et au style de l'écriture arabe. Cette longueur est entretenue par un rituel chez Umm Kulthûm, comparable à celui d'un imâm. Il faut environ à l'imâm une heure de préparation avant la prière. Umm Kulthûm, avant d'entrer sur scène, va faire développer par l'orchestre tout le thème de la chanson.

Vers 1961, je payais cinq dirhams par mois pour écouter Umm Kulthûm dans un café qui s'appelait 'Uchchâq Umm Kulthûm, à Fès, à l'entrée du Mallâh. On payait, on prenait un café au lait et une madeleine et on écoutait Umm Kulthûm, l'hiver à partir de dixsept heures. Jamais le matin. L'été après le coucher du soleil et jamais avant dix heures. Personne ne devait parler ni chanter avec Umm Kulthûm. Il y avait le plus souvent deux chansons du type Yâ zâlemnî, Dhikrayâti, Hagertak, 'Ansâka, Ruba'iyyât al-Khayyâm, Chams al-asîl, etc.

On écoutait 'Abd al-Wahhâb avant, â partir de seize heures. Ou bien à midi, quand le soleil tape car ses chansons étaient courtes et ne pouvaient pas faire une soirée. Il y avait une identification totale à 'Abd al-Wahhâb au niveau du costume : lunettes, tarbouche, cravate.

Aux environs de 1958, on a eu nos premiers chanteurs marocains ; 'Abdelwahab Agoumi, Bahija Idriss, Muhammad Fwîta. On les a détestés! Ces chanteurs voulaient imposer un style marocain (celui des chansons de mariage). Mais cela ne nous parlait pas car il y avait un décalage énorme entre ville et campagne. De plus, ils étaient marocains et le mythe du chanteur ne pouvait se fonder que sur l'extériorité. Un peu comme vous en France avec la chanson de langue anglaise.

Umm Kulthûm avait la possibilité d'être quotidienne et céleste. On respectait ses heures d'écoute comme on respectait l'heure de la prière. Asmahân était la deuxième grande chanteuse adulée.

Aujourd'hui, pour briller, il faut faire le pèlerinage du Caire. C'est le cas d'Abdelwahab al-Doukkali. Dans un premier temps, il a tenté le moule marocain, puis il a décidé d'aller au Caire. Mais il n'a pas le "basbôr al-qâhira ». Si l'un des grands compositeurs égyptiens, notamment 'Abd al-Wahhâb, ne compose pas à un chanteur maghrébin une chanson qui reflète l'originalité égyptienne, il n'a pas son « passeport ». Il est important aussi de savoir si ce chanteur a été applaudi sur une scène cairote. C'est le cas de Bahija Idriss et de Abdelhadi Belkhayât. Ils reviennent toujours avec une composition égyptienne et un 'ûd égyptien. Un 'ûd court, trapu, avec une grande rosace au milieu, en ivoire. Il faut qu'ils aient un rîch $a^{61}$ comme Farîd.

Tout cela, c'était avant $1964 . .$.

En 1958, 'Abd al-Halîm est arrivé. C'était l'Adamo arabe. Ce chanteur marque pour la musique égyptienne le début du déclin.

En 1967, tout s'est effondré. Mais il reste l'héritage culturel. »

\section{Glossaire}

bid'a : Innovation blâmable au regard de la tradition, notamment religieuse. 
dawr (ou dôr, pl. adwâr) : Dans sa forme primitive (1 $1^{\text {ère }}$ moitié du XIX), poème de 4 vers dont les 2 premiers, AA, appelés madhhab, sont suivis des vers BB nommés ghusn (et très souvent dawr). Le plus souvent la partie $B$ comprend 2 ghusn-s (4 vers), l'ensemble $A$ + B étant composé sur le même mètre et chanté sur le même maqâm. Après 1860 environ, madhhab et ghusn sont composés sur des mètres différents et le nombre de vers augmente ( 3 ou 4 pour le maddhab et nombre de ghusn-s en quantité variable). Surtout, ce nouveau dawr combine plusieurs modes dans la composition et cultive la modulation en cours de chant. Il inaugure entre le chœur (sanîda), nouvellement adjoint et le chanteur, une forme de « répons » (hank), sorte de chant alterné où le chanteur répète plusieurs fois certains vers ou fragments de vers combinés selon son goût, apportant à chaque fois des variations « entérinées " par le chœur.

dhikr (pl adhkâi) : Exercice de piété consistant en la «mention » du nom d'Allah et pouvant en certains lieux et circonstances, notamment par la répétition rythmée et le balancement du corps (tafqîr),conduire à un état de transe.

'imâma/'imma : Le premier terme désigne le simple turban, sous toutes ses formes, le second l'ensemble constitué par le tarbûch (ici : calotte en feutre rouge) et le châl, voile blanc de coton enroulé à sa base. C'est la coiffure des cheikhs.

layâlî : Improvisation vocale sur les mots " yâ lêlî, yâ 'ên? (ô nuit, ô [brûlure de] mes yeux) au cours de laquelle le chanteur fait montre de sa virtuosité à l'état pur. Introductif d'autres formes du répertoire dont il sert à présenter le mode (alors sans rythme fixe) ou simple intermède en cours de chant (généralement assis sur le rythme bamb), le layâlî s'individualise comme genre et moment esthétique. La traduction généralement admise (ô nuit, chère nuit) est un contresens. Il s'agit ici de l'œil brûlé par l'insomnie et les larmes du désir de l'aimée.

maqâm (pl. maqâmât): Au sens large, mode, modalité, structure spatiale/tonale à caractéristiques mélodiques précises (structure des intervalles) sur laquelle est bâtie la composition ou l'improvisation.

mawwàl (pl. mawâwîl): Composition poétique en arabe dialectal de 4, 5, 6 ou 7 vers (chatr)donnant lieu à un type d'improvisation vocale basée essentiellement sur la modulation et la structure rythmique du vers.

muwachchah (pl. muwachchahât) : Genre poétique né en Andalousie puis répandu au Moyen-Orient, qui a brisé l'organisation de la qasîda classique par une disposition strophique et des mètres nouveaux. Dans sa version musicale, le muwachchah égyptien revêt des formes très variées, le modèle type se composant d'un thème introductif (dawr ou matla) et d'un "khané» (sorte de couplet) éventuellement séparés d'une " silsila ». Cette forme, assez marginale en Égypte à l'époque de la nahda, a été particulièrement choyée à une époque récente par la musique académique.

nûba (pl. nûbât): Au Maghreb, « suite » musicale intégrant un ensemble de morceaux instrumentaux et vocaux interprétés dans le même mode (tab) dont la nûba tire son nom (ex : nûba zîlân) et suivant une succession de mouvements à rythme propre, fixée par la tradition pour chaque pays, mais dont l'exécution est toujours soumise à la loi de l'accélération progressive.

qafla : «Cadence », pouvant être interne ou finale, généralement exécutée sur la tonique du mode. 
qasîda (pl. qasâ'id) : Adaptation musicale d'un poème en arabe classique d'inspiration profane ou religieuse, mettant en valeur l'improvisation vocale. La qasîda peut être soit composée ou semi-improvisée sur un rythme déterminé (wahda) soit entièrement improvisée et non soumise à un schéma rythmique fixe.

qudûd (sing. qadd) : Chanson populaire de la région d'Alep dérivée du muwachchah mais construite sur des rythmes plus simples.

riqq : Tambourin à cymbalettes.

tahzîm : Acte par lequel le cheikh at-tâ'ifa, après un examen sévère, ceignait du hizâm (ceinture) les chanteurs ou musiciens admis à exercer professionnellement.

tajwîd $l$ taghbir : Il convient de différencier les deux termes, le premier désignant l'orthoépie coranique, i.e. l'art de bien articuler les versets, le second la «cantillation » proprement dite.

takht (pl. tukhûf) : Ensemble instrumental de la musique charqi composé suivant les cas d'un à cinq instruments ('ûd, qanûn, kamân, nây, riqq...)

taqsîm (pl. taqâsîm) : Développement instrumental ou vocal (taqsîm-layâli) d'un mode, improvisation par laquelle l'instrumentiste, par un agencement mélodique et rythmique libre, tente de capter l'essence du mode, d'en exploiter les ressources.

taqtîqa (pl. taqâtîq) : Née avant le siècle et citée souvent comme ancêtre de la chanson légère moderne (ughniyya), elle se compose d'un madhhab (comme le dawr)et de quatre couplets (ghusn-s) se terminant chacun par un retour au madhhab. Cette forme à couplets/refrain en a fait le type de la chanson populaire facile à retenir. D'où sa vogue dès les années vingt, d'abord par le disque, puis au cinéma.

tarab : Émotion esthétique profonde (dérivé peut-être de idtaraba : être troublé) ressentie par le chanteur et transmise à son public.

tatrib : Transmission du tarab parle chanteur (mutrib) à son public.

tawâchih : (cf. muwachchah)

wajd : extase, contemplation mystique, ouverture de l'âme à Dieu.

\section{NOTES}

1. Au moment de la création de la radio irakienne, en 1936, le manque de financements avait conduit à une politique d'importation massive des programmes égyptiens. À cette vacance s'ajoutent d'autres facteurs. En Tunisie, la réécriture propagandiste du folklore local par le bourguibisme avait tourné les oreilles vers les productions venues du Caire. On notera toutefois qu'au Maghreb l'industrie du disque est florissante dès le début du siècle, produisant des artistes locaux.

2. Cf. carte de l'Ezbekiyya : Delchevalerie G., 1899, Les promenades et les jardins du Caire, Chaumes, p. 53. Pour cet aspect très compartimenté de la musique au Caire sous le règne d'Isma'il, cf. Behrens-Abouseif D., Azbakiyya from Azbak to Ismail, IFAO, Le Caire; EBERS G., 1879, Egypt: descriptive historical and picturesque, London, II, p. 29 s. ; HUBER, 1910, plan du Caire.

3. Belleface J.-F., 1989, Turâth, classicisme et variétés: les avatars de l'orchestre oriental au Caire au début du XXe siècle, Damas; Lagrange F., 1988, L'arabe dialectal égyptien dans les chansons d'Umm Kulthûm, aperçu sur la langue des chansons, mémoire de maîtrise, Paris III ; Racy A. J., - 1976, 
«Record Industry and Egyptian Traditional Music: 1904-1932», Ethnomusicology, vol. XX/1, p. 23-48 ; - 1977, Musical Change and Commercial Recording in Egypt, 1904-1932, Thèse de doctorat, University of Illinois, Urbana ; - 1978, « Arabian music and the effects of commercial recording ", The world of music 1/1978, p. 47-55 ; El-Shawan S., - 1980, Al-mûsiqâ al-'arabiyya : a category of urban music in Cairo, Egypt, 1927-1977, Thèse, Columbia University, New-York ; - 1987, " Some aspects of the cassette industry in Egypt ", The world of music, 2/1987, p. 32-45.

4. Târîkh 'âdâb al-lugha al-'arabiyya, Le Caire.

5. On raconte qu'au cours de l'un de ces voyages de la «délégation » égyptienne à Al-'asitâna, le sultan 'Abd al-Hamîd, subjugué par le tarab de ces Égyptiens, avait voulu les retenir définitivement à sa cour et que, effrayé par cette idée, al-Hamûlî aurait trouvé pour "sauver » ses compatriotes l'excuse suivante : chacun d'entre eux étant au service d'un walî (al-Hamûlî luimême serviteur de Sidi Hanafî, Muhammad 'Uthmân de Sayyidnâ al-Hussayn, al-'Aqqâd de l'Imâm al-Châfi'î et al-Manyalâwî d'al-Tachtûchî), tous devaient rentrer en Égypte.

6. On consultera à ce propos $\mathrm{N}$. Loraux, « Modèles féminins du monde antique. Qu'est-ce qu'une déesse ?", Histoire des femmes, t. 1 p. 31-32.

7. Archives de la musique arabe, Ocora, vol. 1, livret p. 6.

8. Lagrange F., 1988, L'arabe dialectal égyptien..., op. cit., p. 12.

9. Abdallah A., 1957 (janv.), Al-'idhâ'a, 1140, p. 18-19.

10. Hafiz N. A., 1984, Al-ghinâ'il al-qarn al-tàsi'a 'achara, Le Caire, p. 37.

11. Wizârat al-Ma'ârif al-'umûmiyya, al-Mamlaka al-Misriyya, 1933, Kitâb mu'tamar al-mûsîqâ al-'arabiyya al-machmûl bi-ri'âyat hadrat sâhib al-jalâla al-malik fu'âd al-awwal al-mun'aqid bi-madinat al-qâhira fî sana 1350 h.-1932 m. (Recueil du Congrès de Musique Arabe réuni au Caire en l'an 1932 sous le Haut Patronage de Sa Majesté le roi Fu'âd ${ }^{\text {er }}$ ), Al-Matba'a al-'amîriyya bi-Bûlâq, p. 18. Désigné infra sub. « Kitâb ».

12. J.-C. Chabrier n'avançait-il pas, de façon plaisante, la théorie selon laquelle la musique savante turque, musique de sérail, donc musique d'eunuques, était une musique sans "éjaculation", autrement dit dépourvue de cette tension cultivée dans le chant arabe et trouvant son « soulagement » dans la qafla!

13. 'Atiyya A. I., 1928, Majmû'at al-mûsîqâ wa al-'aghâni. Le Caire, I, p. 29 s.

14. On lira la belle étude consacrée à ce sujet par F. Lagrange, op. cit. p. $32 \mathrm{~s}$.

15. Al-Musawwar du 7/2/1975, p. 2.

16. Op. cit. p. 40.

17. A Dictionary of Egyptian Arabic, Beyrouth 1986, ix.

18. "Algerian music, as presented at the first conference for arab music in Cairo 1932 ", communication présentée au colloque du CEDEJ de mai 1989 (à paraître).

19. Cf. à ce propos la plainte émise par M. Abu Al-Khidr Mansi, Al-'aghânî wa-l-mûsîqâal-charqiyya bayna-l-qadim wa-l-jadîd, Le Caire, 1965-66, 2e éd., p. 196-97.

20. Cf. à ce propos Rose al-Yûsuf $n^{\circ} 223,29 / 5 / 1932$, p. 26, article de protestation contre l'exploitation des auteurs par les compagnies étrangères.

21. Enquêtes, Paris, Gallimard, p. 28.

22. D'après 'Abd al-Mun'im-Ibrahim, directeur artistique de la compagnie nationale Sôt al-Qâhira, la fabrication et la diffusion du disque laser seraient à l'étude en Égypte, le problème restant celui du coût.

23. 1980, Le sens musical, éd. de Minuit, Paris, p. 55-57.

24. Préface à l'ouvrage de M. 'Abd Al-Rahman, s.d, Al-Chi'r fi mûsiqâ 'Abd Al-Wahhâb, Le Caire, p. 11-12.

25. 1949, Al-mûsîqâ, al-charqiyya bayna al-qadim wa al-jadîd. Le Caire, p. 15 s.

26. Al-râdiû du 27/5/1932, p. 9.

27. Al-idhâ'a, 1140, janv. 1957.

28. Kitâb, 1933, p. 342. 
29. Op. cit. p. 47.

30. Cité par PICHEROT R., 1983, Approches vers les musiques turques, Ministère de l'Éducation nationale, p. 41.

31. Kitâb, 1933, p. 52 s.

32. Ibid.

33. Rose al-Yûsuf $n^{\circ} 221$ du 13/5/1932, p. 25

34. "European comparative musicologists and egyptian music at the Cairo Congress of 1932 ", communication présentée au Colloque du CEDEJ, mai 1989, à paraître.

35. Voir à ce sujet Vigreux P., Le Congrès du Caire et la presse, choix d'articles traduits et commentés, CEDEJ, à paraître.

36. Avril 1932, p. $300 \mathrm{~s}$.

37. Al-râdiû, 8 /7/1932.

38. Fathi Bey M., 1942, Kalimat ma'had fu'âd al-awwal li-l-mûsîqâ al-'arabiyya fi khayr al-wasâil li-nnuhûd bi-l-mûsîqâ al-'arabiyya, Le Caire.

39. Kitâb, 1933, p. 424 s.

40. Rose al-Yûsuf nº 221 du 13/5/1932.

41. Kitâb, 1933, p. 417.

42. Al-Wardi H., 1964, Al-ghinâ'al-'irâqî, Bagdad, p. 170-71.

43. $\mathrm{N}^{\circ} 1042$ (mars 1955), 1047 (avril 1955) et 1048 (avril 1955).

44. $\mathrm{N}^{\circ} 1047$, p. 10 .

45. Cité par Abu 'uf A. C, 1983, Al-lajna al-mûsîq̂̂yya al-'ulyâ fi thalâthîna 'aman, Le Caire, p. 3 et 4

46. On se souvient pourtant que l'audition et l'enregistrement des ensembles de musique populaire égyptienne au Congrès du Caire n'avaient été obtenus que sur l'insistance expresse de membres étrangers comme Béla Bartok.

47. Une opinion analogue sera défendue par le Dr. Fu'âd Zakariyâ ( $D a^{\prime} w a$ ilâ-l-mûsîqâ),lequel, soulignant le caractère obstinément ornementatif du chant arabe conclut, suivant une périodisation occidentale, à l'impasse de cette musique qui n'a «jamais dépassé l'étape du baroque ».

48. Al-Nagmi K., 1972, Sihr al-ghinâ' al-'arabi, Kitâb al-Hilâl, Le Caire, p. 22 s.

49. Audition conseillée : Qâri'at al-finjân (Abd al-Halîm Hâfez, Sôt al-fann, TC 35).

50. Op. cit. p. 27.

51. Al-idhấ'a, n 1147, mars 1957.

52. À Damas, le cheikh Ahmad Abû Khalîl al-Qabbânî est victime d'une cabbale ignominieuse dont on lira les détails dans Kamel M., 1977, Al-masrah al-ghinâ'î al-'arabî. Le Caire, 9-10.

53. Entretien personnel, décembre 1990.

54. «L'Algérie musicale entre l'Orient et l'Occident (1920-1939). Un événement : Le Congrès du Caire de 1932 », communication présentée au Colloque du CEDEJ de mai 1989, à paraître.

55. Muqaddima fî-l-mûsîqà al-'arabiyya, ms. p. 14, cité par Qasim Hasan Sh., « Ikhtiyâr wa tawthîq al-mûsîqâ al-'arabiyya lî mu'tamar al-Qâhira 1932 », communication présentée au colloque du CEDEJ, mai 1989, à paraître.

56. Lagrange F., Arabies, numéro spécial sur la chanson arabe, p. 83.

57. Al-Qubbandji M., 1978, interview télévisée, Bagdad, cité par QASIM HASAN Sh., op. cit.

58. Al-layla al-muhammadiyya al-sâdisa, Al-'Abnudi Abd al-R./Salama G., Sôt al-Qâhira, 90/1093

59. Histoire, culture et société, 1986, Paris, Centre culturel algérien, p. 251-52.

60. Témoignage oral retranscrit par l'auteur, décembre 1990.

61. Le un jeu de plectre rapide et souple. 
INDEX

Mots-clés : centralité, chanson, cinéma, réforme musicale, Umm Kulthûm

\section{AUTEUR}

PHILIPPE VIGREUX

Cedej 